\title{
Recent Trends in Photocatalytic Materials for Reduction of Carbon Dioxide to
}

\section{Methanol}

\section{O. Adekoya, ${ }^{a}$ Muhammad Tahir ${ }^{\mathrm{b}}$ and NAS. Amin ${ }^{\mathrm{b}}$}

${ }^{\text {a }}$ Center for Clean Environment and Energy, Environmental Futures Research Institute, Griffith School of Environment, Griffith University, Gold Coast Campus, Southport, QLD 4222, Australia

a, b Chemical Reaction Engineering Group (CREG), School of Chemical and Energy Engineering, Faculty of Engineering, Universiti Teknologi Malaysia, 81310 UTM Johor Bahru, Johor, Malaysia.

*Corresponding Author: noraishah@cheme.utm.my

\begin{abstract}
One of the promising approaches to alleviate the problems associated with energy crisis and global warming is through photocatalytic reduction of $\mathrm{CO}_{2}$ to hydrocarbon fuels. Ultimately, photocatalytic processes utilize solar energy to convert $\mathrm{CO}_{2}$ into hydrocarbon fuels by deploying effective photocatalysts. Among the solar fuels produced from $\mathrm{CO}_{2}$ photoconversion, methanol is a versatile feedstock for producing numerous chemicals in the industry. The success of a photocatalytic conversion process hinges on the type of photocatalyst material. Although $\mathrm{TiO}_{2}$ is considered a very viable candidate due to its availability, non-toxicity, ease of synthesis and affordability, its large band gap and inability to absorb in the visible region has necessitated research into other materials. For several years researchers have reported different viable materials for this process leading to improvements in the catalytic activity. However, actualizing the conversion efficiency desired from the solar energy to produce fuels still requires modification of existing materials and discovery of new ones. The objective of this review is to provide an in-depth systematic information on different photocatalysts that have been used over the years and discuss factors that
\end{abstract}


influence their effectiveness. Various modification methods for tuning the properties and improving the performance of photocatalysts are discussed. Composites or heterostructures synthesized through these modification methods are also evaluated. Comparative analysis of the performance of these composites or heterostructures with that of $\mathrm{TiO}_{2}$ is presented in this review followed by useful, applicable suggestions and recommendations for future progress.

Keyword: Photocatalyst, Carbon dioxide, Photocatalytic reduction, Methanol.

\section{Contents}

1. Introduction

2. Basics of Heterogeneous Photocatalytic Processes 12

2.1. Principles of Photocatalysis 12

2.2. Thermodynamic barriers for methanol production 13

2.3. Selection of materials for methanol production $\quad 14$

3.0. Advancements in $\mathrm{CO}_{2}$ Photoreduction: Photocatalytic Material Review 15

3.1. $\mathrm{TiO}_{2}$-Based Photocatalysts $\quad 15$

3.1.1. Doping 16

3.1.1.1. Metal Doping 17

3.1.1.2. Non-Metal Doping 20

3.1.1.3. Co-Metal doping $\quad 21$

3.1.2. Modification by formation of Metal Oxides 23

3.1.3. Modification by formation of Nanomaterials 24

3.1.4. Modification by Sensitization $\quad 27$ 
3.1.6. Metal-Ligand Charge Transfer 32

3.2. Substitutes for $\mathrm{TiO}_{2}$ based photocatalysts for $\mathrm{CO}_{2}$ photoreduction 37

3.2.1. Metal oxides and hydroxides $\quad 39$

3.2.2. Metal organic frameworks \& mesoporous materials $\quad 41$

3.2.3 Oxysalts 42

3.2.4. Metal Chalcogenides \& nitrides $\quad 47$

3.2.5. Polymeric Materials 48

4. Challenges and Recommendations 53

5. Concluding remarks $\quad 57$

$\begin{array}{lr}\text { Acknowledgments } & 59\end{array}$

$\begin{array}{ll}\text { References } & 60\end{array}$

\section{Introduction}

Although industrialization and technological advancement is a major booster to the global economy, many of the activities attributed to this improvement have contributed to the gradual destruction of our ecosystem. Hazardous effluents and by-products have cut short the life expectancy of human beings, adversely affected the growth and development of plants and animals and polluted air, land and water [1]. Global warming has been identified as a root cause of several problems threatening the existence of humankind, animals and the earth itself. Global warming contributes little or no positive effects to the earth and its adverse effects trickles down to every sphere of life (our communities, health and climate). Irregular/extreme heat, rising sea level resulting in coastal flooding, extensive and damaging wildfires, dangerous hurricanes, worsening air pollution, prevalent diseases, destruction of marine life, 
extensive drought seasons, disrupted food supplies and abrupt climate change are just the beginning. The future of our planet as we know it is very bleak because of the culminating effect of global warming; the slightest changes in the temperature of the earth is resulting in drastic changes to our ecosystem [2]. The 2018 report of the Lancet Countdown on health and climate change shows that we are more vulnerable to extreme weather changes, vector and water borne diseases, financial losses from climate-related events such as hurricanes and storms all due to global warming [3].

While governments and international organizations claim to be making efforts to develop and improve existing health and climate change monitoring systems, they continue to fund/support industries and activities which encourage global warming. Although the Paris agreement was signed by 187 countries who committed to reduce greenhouse emissions at their national level, many still fail to meet the agreement leaving the possibility of achieving the aims of the agreement at limbo [4]. Several countries still focus on the use of fossil fuels for power generation though they claim to have embarked on a low-carbon path, industries and activities which contributes to carbon footprint must be fully eradicated for significant progress to be achieved [5]. Flue gas emitted from industries mostly contains: carbon monoxide $(\mathrm{CO})$, sulphur dioxide $\left(\mathrm{SO}_{2}\right)$, nitrogen dioxides $(\mathrm{NO})$, other hydrocarbons and carbon dioxide $\left(\mathrm{CO}_{2}\right)$ are collectively known as greenhouse gases and are responsible for the greenhouse effect associated with global warming.

Although $\mathrm{CO}_{2}$ can generally be considered harmless (at least physiologically to plants and animals - including humans), the quantities of about 6 billion tons released annually into the atmosphere has led to climate and health altering effects. In humans, extreme heat due to global warming has led to heat stroke, triggered existing heart failure, frequent cases of acute kidney injury due to dehydration, chronic cardiovascular and renal diseases in old and young, drug resistant bacteria and vectors with diseases such as dengue, diarrhoeal and malaria 
becoming more prevalent. Animals such as polar bears are losing their homes while aquatic life and coral reefs are being lost due to a combination of extreme heat, air pollution and water pollution [3]. Of all the greenhouse gases, $\mathrm{CO}_{2}$ is identified as the primary source with methane $\left(\mathrm{CH}_{4}\right)$, nitrous oxide $\left(\mathrm{N}_{2} \mathrm{O}\right)$ and fluorinated gases (hydrofluorocarbons, perfluorocarbons and sulphur hexafluorides) as the other contributors. Greenhouse gases are predominantly generated by the following activities: electricity and heat generation, industrial activities, agricultural activities, transportation, onsite energy generation such as burning fuels for heating in homes and other energy production processes. These activities are all prevalent in our society it is therefore obvious that human activities are fundamental to solving the issue of greenhouse gas emissions and global warming $[6,7]$.

On the other hand, another issue of concern in the world today is clean energy generation and its sustainability. The need for energy cuts across every aspect of our life and it indicates the level of industrialization and economic expansion of any nation [8]. This need for greater sustainable and clean energy supply has led to the movement for a "transition from fossil fuels" [9]. The "transition" from fossil fuel energy is evident in different countries because there has been an increase in energy generated from renewables. For example, the United States of America sourced up to $17 \%$ of its electricity from renewables in 2018 according to the US Energy information Administration [10] In fact, the addition of renewable energy sources saw the United States reduce its $\mathrm{CO}_{2}$ emissions per capita from 16.5 in 2014 to 15.56 in 2016 as it generated up to $17.64 \%$ from renewable sources in 2016 (but only $13.39 \%$ in 2014) [11]. However, despite the progress made in the US it is important to take a global perspective, the $\mathrm{CO}_{2}$ emissions per capita of oil producing countries (such as Saudi Arabia, Kuwait, Qatar and United Arab Emirates) continue to rise [12, 13]. Most of these countries rely on fossil fuels because they have it in abundance and make a lot of money from trading it. Also, the cost of establishing renewable energy sources such as wind farms, solar 
farms, hydro-electric power and geothermal energy systems are still too high for developing countries, so they rely on fossil fuels. Therefore, there is still a need for more sustainable and clean sources of energy. Another perspective is the depletion of existing resources, according to the US Energy Information Administration, as at January 2018 the world reserve of natural gas was estimated at about 7,124 trillion cubic feet (Tcf) and majority of the proved reserves were in the Middle East and in Russia [14]. This has a significant impact on the world's energy balance. As per estimation, at the current rate of use, the reserves are expected to last for about 50 years only [15]. Hence, an alternative source of energy that cannot be monopolized, that is sustainable and can provide a simpler and cleaner fuel is of importance.

Considering nuclear, geothermal, wind, hydroelectric, and solar sources of energy, although they do not emit a considerably large amount of $\mathrm{CO}_{2}$ or other greenhouses gases, the cost, safety and life cycle of these energy sources are of concern. For example, people living near wind turbines are often at the risk of Chronic sleep disturbance, absorption of infrasound which causes wind syndrome associated with symptoms such as tinnitus [16]. Some countries still use nuclear energy as a source of clean energy as there are no emissions although when there is an accident like the case of Chernobyl, the effects are catastrophic. Apart from the cost of establishment, the level of trust in safety of using nuclear reactors for energy generation varies, some people believe it is safe while others have a different perspective and this is based on different criteria such as gender etc. [17]. Some reports suggest that shading caused by PV panels for solar energy generation will lead to changes to wind flow, and could alter temperature, change rainfall distribution (which affects soil moisture) and disrupts wind flow over the land [18]. Hydroelectric [19] and Geothermal [20] energy generation are not entirely clean energy processes because their plants still generate some greenhouse gases and they are quite expensive to set up. For every alternative there is a problem attributed to it, perhaps there is no silver bullet to address the issue of renewable energy or global warming. To this 
end, a multidisciplinary approach might be the most reliable way - a combination of different technologies to solve the major issue facing humankind [21]. Transforming energy from one form to another can be achieved through different routes and the use of solar energy can be regarded as a sustainable alternative considering it is primarily sourced from the sun. One application of solar energy to solve the problem of global warming and increasing clean energy demand is the conversion of $\mathrm{CO}_{2}$ to hydrocarbon fuels $[22,23]$.

The conversion of $\mathrm{CO}_{2}$ into useful hydrocarbon fuels (e.g., methanol) is a viable route for clean energy generation as it tackles two of the issues facing mankind. [24]. Known also as artificial photosynthesis, photocatalytic conversion of $\mathrm{CO}_{2}$ using solar energy is considered as a feasible approach for the transformation of $\mathrm{CO}_{2}$ to hydrocarbon fuels [25]. The interest in this field has been aroused dramatically after several demonstrations on photocatalytic reduction of $\mathrm{CO}_{2}$ to organic compounds debuted in 1970s [25]. The pace has recently increased enormously, because of the focus on advanced technologies (e.g. nanotechnology and in-site advanced characterization) for development of novel photocatalysts [26]. Various methods exist for harvesting solar energy and the use of photocatalysts provides a viable option because of the reversible oxidation-reduction capabilities. Photocatalytic $\mathrm{CO}_{2}$ reduction is a two-way process which involves; $\mathrm{CO}_{2}$ recycling and production of useful chemical fuels. The process involves the use of a photocatalytic material to deploy solar energy and its reaction with $\mathrm{CO}_{2}$ in either aqueous or gas phase system [27]. The properties of the photocatalytic materials through photo-oxidation reactions could reduce carbon dioxide to different hydrocarbon fuels such as methanol, formic acid, formaldehyde, methane and hydrogen. These hydrocarbon fuels can then be used as a fuel and a raw material for different applications [24].

The type of photocatalyst materials for photoreduction of $\mathrm{CO}_{2}$ is a critical factor in a photocatalytic process as it determines several key details of the process. Some of these key 
details include: the reaction pathway, the type of light that would be absorbed and used for the process, the likely products obtainable from the process and ultimately the effectiveness and yield of the process [28]. Therefore, the choice of photocatalyst material is very crucial and therefore it has been the focus of research in this field. Various material categories ranging from metal oxide semiconductors to sulphides, nitrides, and carbides to carbonaceous materials to quantum dots, dyes and enzymes have been reported as promising photocatalysts. Metal oxide semiconductors such as titanium oxide $\left(\mathrm{TiO}_{2}\right)$, tungsten oxide $\left(\mathrm{WO}_{3}\right)$, and zinc oxide $(\mathrm{ZnO})$ etc. are widely used for photocatalytic conversion of $\mathrm{CO}_{2}$ [29]. Amongst the metal oxide semiconductors, $\mathrm{TiO}_{2}$ is a commonly used photocatalyst due to its attractive properties. These properties include; availability and affordability, good charge transfer potentials, safety and corrosion resistant, powerful oxidation properties and ease of tunability $[30,31]$. Unfortunately, $\mathrm{TiO}_{2}$ only possesses UV light (wavelength less than $380 \mathrm{~nm}$ ) activity because it has a high band gap (3.20 eV for anatase) [30, 32]. This implies that under visible light (which is the largest part of the solar spectrum) $\mathrm{TiO}_{2}$ is mostly inactive in this region of the spectrum. Overcoming this limitation is possible through different modification methods which will be discussed later in this review. Although it is possible to achieve VLR $\mathrm{TiO}_{2}$ using modification methods, other photocatalysts which are VLR active have been reported for $\mathrm{CO}_{2}$ photoreduction. The photocatalysts demonstrated higher photo-activity than $\mathrm{TiO}_{2}$ in most cases especially under visible light irradiations. Most of these VLR photocatalysts are metal/non-metal oxides such as $\mathrm{WO}_{3}, \mathrm{NiO}_{2}, \mathrm{In}_{2} \mathrm{O}_{3} \mathrm{TaO}_{4}, \mathrm{Fe}_{2} \mathrm{O}_{3}, \mathrm{Bi}_{2} \mathrm{O}_{3}$ etc [33]. Although VLR photocatalysts have reported higher photo-activity and product yield compared to UV sensitive $\mathrm{TiO}_{2}$, selecting/highlighting a material as the best is not accurate as most reported works are carried out under varying reaction and experimental conditions. Also, the accuracy and credibility of some reported photocatalytic systems is questionable because in some cases it is difficult to ascertain the origin of the electrons used for the photoreaction [34]. Thus, more 
research is needed to further understand the process and to optimize existing materials as well as discover new viable photocatalytic materials.

Although the band gap of the photocatalyst material dictates its photo-activity, its efficiency as a material is also affected by other properties. These include ability to absorb $\mathrm{CO}_{2}$, availability of interconnected porous network, easy migration of electrons through pathways and a large surface area. All these properties are related to its structure or morphology. Bulk materials are mostly non-porous; hence they are not able to accommodate enough adsorbate needed for optimum reaction efficiency. This limitation spurred research into nanostructured materials for optimum $\mathrm{CO}_{2}$ photoreduction. Nano sized materials such as nanotubes, nanorods, and nanofibers have helped to improve the performance of photocatalytic materials due to several advantages including high surface to volume ratio, better adsorption rate, improved light absorption efficiency and rapid migration of electrons. These properties have improved the effectiveness of photocatalytic materials, increased product yield as a result of a boost in the overall efficiency of the process [35]. Material design is very critical in photocatalytic processes because as band engineering tunes band gap, material design restructure and optimize materials for effective performance. Design of materials with core-shell, yolk-shell, multi-shell, hollow structures have helped to improve performance by reducing the transport distance of holes and electrons. However, most of these unique morphologies are synthesized by multi-step complex methods which sometimes use toxic, expensive or non-sustainable materials. Also, during some of these synthesis methods, the photocatalytic property of the material such as its band gap could be altered. For example, it is possible to create oxygen vacancies on a nanostructured material during its synthesis. These oxygen vacancies can positively impact the reaction pathway but while they might improve a specific process, they might also facilitate the occurrence of side-reactions. Hence, it is important to consider the effect of synthesis method and structural modification on the 
photocatalytic reaction [36-38]. The challenge with band gap engineering relates to having a photocatalyst material which possess a medium or low band gap suitable for the desired process and matching the band gap to thermodynamic reduction potential demands $[32,39]$. Meanwhile, the challenge experienced with material design is the synthesis of a morphology or structure which provides a large surface area, interconnected network of pores available for easy transport of electrons while maintaining the band engineering of the material. Therefore, it is evident that more research work is needed in the design and tuning of materials for effective photocatalytic processes.

In terms of photocatalyst materials and hydrocarbon/solar fuels, there is a relationship between the two and the linkage between them is the band gap of the photocatalyst material and the redox potential of reaction between $\mathrm{CO}_{2}$ and $\mathrm{H}_{2} \mathrm{O}$. As a general rule, for a photocatalyst material to effectively transfer electrons to the adsorbed $\mathrm{CO}_{2}$, the relative potential level of the acceptor is thermodynamically required to be more positive than the conduction band (CB) of the semiconductor [40]. This implies that for a photocatalyst to yield methanol as a product, it is required for its $\mathrm{CB}$ to be more negative than $-0.38 \mathrm{eV}$, which is the reduction potential for half-cell reduction reaction of $\mathrm{CO}_{2}$ to methanol in $\mathrm{H}_{2} \mathrm{O}$ at $\mathrm{pH} 7 \mathrm{vs}$ NHE. Aliwi et al. [41] demonstrated this by reducing $\mathrm{CO}_{2}$ to formic acid and formaldehyde using $\mathrm{CdS}$ as a photocatalyst. $\mathrm{CdS}$ has a $\mathrm{CB}$ of $-1.0 \mathrm{eV}$ while the reduction potential for both hydrocarbon fuels are -6.1 and $-5.2 \mathrm{eV}$. Based on the fulfilment of the thermodynamic criteria, the reaction was possible. Although this perspective is right and has been proven several times, the efficiency and selectivity of a photocatalyst material is dependent on more than the band gap, thermodynamic reduction potential or $\mathrm{pH}$. An in-depth study of these factors is presented in this review. Photoreduction of $\mathrm{CO}_{2}$ can yield several hydrocarbon fuels including carbon monoxide, methane, formaldehyde, formic acid, acetic acid, ethanol and methanol. Methanol serves as a major basic feedstock in the production of several organic compounds, a vital 
intermediate for several chemicals used in everyday products such as silicone, paint, and plastics [42]. It could also serve as an alternative to gasoline in the future. Methanol is also currently used in an electrochemical device that converts chemical energy of fuels into electrical energy. The Direct Methanol Fuel Cell (DMFC) is rapidly developing as a prospective energy storage device and it is currently used to supply power to small electronic devices such as mobile phones and laptop and tablet computers [43]. Also, in liquid form it provides a safer and convenient way for storing energy unlike gasoline. Methanol is also used in the process of transesterification for the conversion of triglycerides to produce useful fuels known as biodiesel. Methanol is produced from synthesis gas (syn. gas), - a mixture of carbon monoxide, carbon dioxide and hydrogen, in large scale industrial plants for commercial purposes at millions of tons per year. $[44,45]$. It can also be produced from the conversion of methane, e.g., selective oxidation of methane, catalytic gas phase oxidation of methane, liquid phase oxidation of methane, mono-halogenations of methane, and microbial or photochemical conversion of methane [44]. Reduction of carbon dioxide to produce methanol provides a highly attractive solution by recycling carbon dioxide into useful chemicals and sources of alternative energy simultaneously making the earth safer for mankind and animals to co-exist [42].

Considering the importance of solar assisted carbon dioxide conversion to hydrocarbon fuels and several synthetic hydrocarbons and chemicals which use methanol as a raw material, methanol can be regarded as a versatile and widely used hydrocarbon fuels from this process [46]. Therefore, we present one of the first reviews to exclusively discuss photoreduction of $\mathrm{CO}_{2}$ to methanol focusing on materials. This review gives an overview of different materials explored for photoreduction of $\mathrm{CO}_{2}$ to methanol. It highlights important criteria for an effective material for $\mathrm{CO}_{2}$ photoreduction and how these affect the efficiency of the process and yield of products. Different methods for modifying and designing better 
materials for photoreduction of $\mathrm{CO}_{2}$ are provided. The discussion ends with an assessment of the "methanol economy" and a perspective on the way forward.

\section{Basics of Heterogeneous Photocatalytic Processes}

\subsection{Principles of Photocatalysis}

Heterogeneous photocatalytic process involves one or more reaction steps occurring by means of electron pairs photo-generated on the surface of a semi conducting material illuminated by light of suitable energy. This type of pathway is totally different from the usual thermal reaction sequence and leads to product selectivities different from those for thermal/catalysed reactions [47]. Unlike other reaction pathways, the absorption of irradiated light by a semiconductor of comparative band gap is the beginning of a photocatalytic reaction. This absorbed photonic energy is then used to activate the reductive process for which the system is designed which is mostly dye or pollutant degradation for water purification or photoreduction of $\mathrm{CO}_{2}$ to renewable chemicals. Semiconductors are filled with clusters of electronic energy levels which results in two bands; the highly electron dominated valence band denoted VB and the high energy conduction band (CB) as shown schematically in Fig. 1. These bands are separated by a region known as the band gap through which electrons migrate from the populated $\mathrm{VB}$ to the vacant region of $\mathrm{CB}$ resulting in the creation of a positive charged hole $\left(\mathrm{h}^{+}\right)$species in the VB of the photocatalyst. This migration of photoactivated electrons can only be accomplished if the band gap of the said photocatalyst is less than that of the incident light. Without this successful electron transport from the VB to the $\mathrm{CB}$ a photocatalytic reaction will not occur because the photogenerated electron and hole species facilitate photoreactions at the surface of the photocatalyst.

The design of photocatalytic materials with optimum efficiency and effectiveness is dependent on different parameters which are not limited to; suitable band gap which aligns 
with the region (wavelength) of irradiated light in the spectrum and inhibition of electron-hole recombination by using appropriate photocatalyst modification method. Furthermore, the particle size and surface area, dispersal or deposition method (i.e. dispersed in reductant or coated on a substrate) of the photocatalyst and consideration of the NHE potential of the desired product as it relates to the band gap of the photocatalyst must be considered. To put things in perspective, without migration of photoactivated electrons from the VB of a photocatalyst to its $\mathrm{CB}$ a photoreaction cannot be initiated however the success of the photocatalytic reaction depends on several other factors with inhibition of recombination playing a key role [48]. In the absence of suitable adsorbates, electron-hole pair recombination occurs with release of thermal and/or light energy [49].

\subsection{Thermodynamic barriers for methanol production}

While the electron-hole pair exists, the photocatalyst can perform useful reduction and oxidation reactions by accepting electrons into its valence band or donating the promoted electrons in its conduction band. When an electron moves to the surface of the photocatalyst and has the correct potential, anion radicals are produced, while cation radicals are produced from electron holes at the surface. Generally, it is preferable that the redox potential of a donor species adsorbed on the photocatalyst surface be more negative (higher in energy) than the valence band position of the semiconductor in order to refill the electron vacancies. Likewise, acceptor molecules must have a redox potential more positive (lower in energy) than the conduction band $[48,50]$. Therefore, the redox potential and band energy are two criterions for electron transfer in a photocatalytic process. If we consider the reduction potentials for half-cell reactions in aqueous solution in Table 1, the electrons from the semiconductor must have a more negative redox potential than that of water splitting for $\mathrm{CO}_{2}$ photoreduction to hydrocarbons to occur [51]. For $\mathrm{CO}_{2}$ to be converted to methanol the semiconductor to be 
used must have a $\mathrm{CB}$ more negative than $-0.38 \mathrm{eV}$ otherwise the result will be a water splitting reaction instead of $\mathrm{CO}_{2}$ photoreduction. Thus, for methanol production a suitable semiconductor to use is one with a $\mathrm{CB}$ less positive compared to $0.38 \mathrm{eV}$. e.g. considering $\mathrm{TiO}_{2}$ with a $\mathrm{CB}$ of $-0.50 \mathrm{eV}$, its $\mathrm{CB}$ is less positive than the required energy to convert $\mathrm{CO}_{2}$ to methanol. Hence thermodynamically, using $\mathrm{TiO}_{2}$ as a photocatalyst for reduction of $\mathrm{CO}_{2}$ to obtain methanol would be feasible [52].

\subsection{Selection of materials for methanol production}

Choice of photocatalytic material used for $\mathrm{CO}_{2}$ photoreduction an important factor that determines the effectiveness of the process. It dictates the band gap of the photocatalyst material. The band gap of the semiconductor is very important for an effective photocatalytic process to occur because the light absorption capacity and charge carrier generation of the semiconductor is dependent on the band gap. Likewise, it is preferable that the VB and CB be slightly greater than the redox potentials required for the process. However, most photocatalysts with wide-band gaps do not absorb great amount of light. For example, $\mathrm{TiO}_{2}$ has a band gap of $3.2 \mathrm{eV}$ (Fig. 2.) Which reduces its light absorption to less than $390 \mathrm{~nm}$. Therefore, the conversion efficiency of the photocatalytic process is low. The first and second criterions (the redox potential of desired products and the band gap of the specific photocatalyst) are related and both determine the effectiveness of a photocatalyst for a specific process [53].

Fig. 2 shows the band gap of a group of photocatalysts with respect to the redox potential of different possible products at a $\mathrm{pH}$ of neutrality (7) [53]. The type of products that can be formed from the process depends on the relationship between the band engineering and the redox potential of the product of choice. The band energy of the top part of the CB dictates the reductive power of electrons in the photocatalyst. Conversely the oxidative strength of 
holes in the photocatalyst is dependent on the energy of the lower part of the photocatalyst, VB. To this end, for a photocatalyst to yield a product, the band energy of the CB should be higher than the potential of producing that product. From Fig. 2, $\mathrm{TiO}_{2}$ and $\mathrm{CdS}$ are shown to produce hydrogen and oxygen while $\mathrm{WO}_{3}$ and $\mathrm{Fe}_{2} \mathrm{O}_{3}$ can only oxidize water (to give $\mathrm{O}_{2}$ ) but cannot reduce it (to give $\mathrm{H}_{2}$ ). The relationship between redox potential and band gap also relates to $\mathrm{CO}_{2}$ for reduction to different hydrocarbon fuels e.g. $\mathrm{H}_{2}$, methanol, formic acid, methane etc.

Apart from mismatching between the absorption ability of semiconductor and the solar spectrum due to their wide band gap energy, there are other challenges. Poor charge carrier separation efficiency, low solubility of $\mathrm{CO}_{2}$ molecule in water for aqueous processes (approximately $33 \mu \mathrm{mol}$ in $1 \mathrm{ml}$ of water at $100 \mathrm{kPa}$ and room temperature), reversed reactions during reduction of $\mathrm{CO}_{2}$ and water splitting are some of the challenges [27]. Over the years several strategies have been employed to increase the process efficiency. The efficiency of any photocatalytic process is largely dependent on the choice of photocatalytic material used, the nature of the system and the operating parameters or conditions that ensure optimal performance. Of all the factors listed, the choice of photocatalytic material plays a major role because it dictates the pathway of the photoreaction. Therefore, our first focus in this review highlights the developments in photocatalytic materials used for photoreduction of $\mathrm{CO}_{2}$.

\subsection{Advancements in Photocatalytic Material for $\mathrm{CO}_{2}$ Reduction}

\section{1. $\mathrm{TiO}_{2}$ - Based Photocatalysts}

Amongst the semiconductors widely used for $\mathrm{CO}_{2}$ photoreduction Titanium dioxide $\left(\mathrm{TiO}_{2}\right)$ is a widely investigated for photocatalytic reactions. This is because of its properties e.g. high photo-activity, suitable optical/electronic qualities, low cost and availability, low toxicity and earnest chemical and thermal stability [54]. It provides enough negative and 
positive redox potentials for the photocatalytic process. It exists in three different polymorph structures - anatase, rutile and brookite. Of the three crystalline configurations, anatase has the highest level of photoconductivity with a band gap of $3.2 \mathrm{eV}$. Rutile is the least photo reactive of the three due to its more proficient recombination of the electron hole pair and smaller surface area [55]. Several researches have been carried out using pure $\mathrm{TiO}_{2}$ for photoreduction of $\mathrm{CO}_{2}$ to methanol, but despite the numerous studies using bare $\mathrm{TiO}_{2}$ for photocatalytic conversion of $\mathrm{CO}_{2}$, it is still limited in its efficiency. Relatively poor charge transport property and, fast recombination rate of its photo-induced electron-hole pairs, low oxygen production after absorption of UV photons and wide band gap of approximately 3.2 $\mathrm{eV}$ are its main limitations [56].

The other concern is the light used for photocatalysis. UV photosensitive catalysts are limited because UV light that reaches the earth is only $3-5 \%$ of the solar irradiation. Thus, it is important for photocatalyst to be sensitive to visible light. Taking $\mathrm{TiO}_{2}$ as an example, high energy input is required for it to be activated, but the high energy photons that exists in the UV region is only $4 \%$ of the total energy. Therefore, the efficiency of $\mathrm{TiO}_{2}$ is minimized. In order to overcome these limitations various surface modification techniques have been employed such as doping, dye sensitization [57] and combination with Quantum Dots (QDs) [58], synthesis of composite semiconductors [59], and formation of heterostructures [60] and nanostructures [61]. The different technologies for $\mathrm{CO}_{2}$ photoreduction and different modification methods for photocatalysts are exhibited in Fig. 3.

\subsubsection{Doping}

One of the most common and perhaps oldest methods of modifying the properties or aligning the band engineering of a semiconductor is by doping it. One advantage of doping is that most of the metal dopants (especially transition metals having plasmonic properties) can 
act as electron trapping agent thereby, enhancing charge separation and improving the efficiency of the photocatalyst [62]. Also, doping has been reported to create a strong imaginary electric field at the interface of the metal-semiconductor. The presence of this electric field leads to an increase in the number of charge carrier species at the interface of the metal-semiconductor. The charge carrier species are then able to migrate to the surface where they are used in redox reactions [63]. Modification of a semiconductor by doping has proven to be a successful approach to improving the efficiency of a photocatalyst.

\subsubsection{Metal Doping}

The purpose of doping a semiconductor is to introduce impurities into its pure structure for adjusting its electrical properties. Pure $\mathrm{TiO}_{2}$ with its $3.2 \mathrm{eV}$ large band gap is unable to absorb high photon energy but doping helps to decrease its band gap energy. In metal -doped $\mathrm{TiO}_{2}$ photocatalysts the electrons are transferred from the $\mathrm{CB}$ to the metal dopant. Doping has been researched with metals, non-metals, noble metals, transition metals and rare-earth metals. Doping process has been carried out using several methods such as impregnation method [64], sol-gel method [65], co-precipitation [66], metal-ion implantation [67] and RF magnetron sputtering method [68]. Common metals used to dope $\mathrm{TiO}_{2}$ include $\mathrm{Cu}, \mathrm{Ag}, \mathrm{Fe}$, $\mathrm{Cr}, \mathrm{Pt}$, and $\mathrm{Rh}$. A transition metal is used to modify the band gap of $\mathrm{TiO}_{2}$ by doping it into its structure. In this type of heteroatom doped photocatalyst, photoconversion of $\mathrm{CO}_{2}$ takes place on the doped metal atom. When photo-excitation occurs and electrons are transferred from the VB to $\mathrm{CB}$, these electrons are further transferred to the metal heteroatom upon which conversion of $\mathrm{CO}_{2}$ occurs. Doping of the heteroatom on $\mathrm{TiO}_{2}$ causes an alteration in its band gap thereby shortening it to $<3.2 \mathrm{eV}$. Most transition metals such as $\mathrm{Au}$ and $\mathrm{Ag}$ possess additional effect known as the localized surface Plasmon resonance (LSPR). Fig. 4 shows the photocatalytic mechanism and LSPR effect of $\mathrm{Ag} / \mathrm{TiO}_{2}$ (a), comparison of photocatalytic 
activity of pure $\mathrm{TiO}_{2}$ and $\mathrm{Ag}$ modified $\mathrm{TiO}_{2}$ under UV (b) and visible light (c). This effect contributes to a strong absorption of the visible light [69]. Therefore, they can improve the photo-activity of the photocatalyst material hence its performance under the visible light illumination. When combined with UV sensitive photocatalysts such as $\mathrm{TiO}_{2}$, metals which possess the LSPR effect such as gold nanoparticles can efficiently transfer electrons to the conduction band (CB) of $\mathrm{TiO}_{2}$ under visible light irradiation. Through this transfer from the gold nanoparticles, UV light sensitive $\mathrm{TiO}_{2}$ can function as a VLR photocatalyst because provided by doping it with $\mathrm{Au}$. This can then result in prolonged recombination time, instant charge separation and an enhanced photocatalytic behaviour in the photocatalyst which could be attributed to the SPR effect of Au nanoparticles. Due to the LSPR effect of the metal, the photocatalyst can accept electrons from external donors and use this for reduction of $\mathrm{CO}_{2}$ to $\mathrm{CO}, \mathrm{CH}_{4}$ and methanol after faster rate than usual. This is similar to the report given by Tahir et al [70]

When a metal is doped into an n-type semiconductor e.g. $\mathrm{TiO}_{2}$ if the work function of the metal $W_{m}$ is greater than that of the semiconductor $W_{s}$ (i.e. $W_{m}>W_{s}$ ) holes from the semiconductor cannot easily migrate to the metal. This is because a Schottky barrier forms at the interface of the metal-semiconductor. Conversely, when $W_{m}<W_{s}$ a charge accumulation layer is formed at the interface and this prevents formation of the Schottky barrier hence electrons are free to move in any direction [71]. However, for a p-type semiconductor e.g. $\mathrm{Cu}_{2} \mathrm{O}$ doped with a metal e.g., $\mathrm{Pd}$, if $W_{s}>W_{m}$ the migration of holes from the semiconductor to the metal is made easy by migration of charge carriers. This would ensure the chances of recombination is reduced [63]. These shows that the choice of dopant is very crucial to the pathway and the mechanism of the photocatalyst determines the type of reactions and the products obtained. For example, using $\mathrm{Pt}$ as a dopant for $\mathrm{TiO}_{2}$ produces higher methane yield than methanol from $\mathrm{CO}_{2}$ photoreduction. This is because since $W_{P t}>W_{T i O 2}$ photo-generated 
electrons can be transmitted through the metal atom thereby fostering charge separation and inhibiting recombination [72].

Amongst all the metals used for $\mathrm{CO}_{2}$ photoreduction (Pt, $\mathrm{Au}, \mathrm{Ag}, \mathrm{Pd}, \mathrm{Ru}, \mathrm{Rh}, \mathrm{Cu}$, and $\mathrm{Zn}$ etc.), copper $(\mathrm{Cu})$ and silver $(\mathrm{Ag})$ have been mostly used to improve the photo-activity of $\mathrm{TiO}_{2}$ and selectivity of methanol production during photoreduction of $\mathrm{CO}_{2}$. Fig.. 4. Shows the photocatalytic Mechanism of $\mathrm{Ag} / \mathrm{TiO}_{2}$ (a) and a comparison of photocatalytic activity of pure $\mathrm{TiO}_{2}$ and $\mathrm{Ag}$ modified $\mathrm{TiO}_{2}$ under UV (b) and visible light (c). Several reports have shown that $\mathrm{Cu}$ doped $\mathrm{TiO}_{2}$ photocatalysts are very efficient to convert $\mathrm{CO}_{2}$ and $\mathrm{H}_{2} \mathrm{O}$ to methanol ($0.38 \mathrm{~V})$ and this can possibly be traced to the reduction potential of $\mathrm{Cu}\left(\mathrm{Cu}^{2+} / \mathrm{Cu}=+0.337\right.$ V). Although the oxidation state of $\mathrm{Cu}$ determines its reaction pathway, using $\mathrm{Cu}_{2} \mathrm{O}$ as an example, its $\mathrm{VB}$ and $\mathrm{CB}$ are located above that of $\mathrm{TiO}_{2}$ facilitating the photo-generated electrons to migrate from $\mathrm{Cu}_{2} \mathrm{O}$ to $\mathrm{TiO}_{2}$. This simultaneously create holes in the $\mathrm{VB}$ of $\mathrm{Cu}_{2} \mathrm{O}$ thereby ensuring separation of electron-hole pairs. The migration enables rapid conversion of $\mathrm{CO}_{2}$ to methanol and the separation inhibits occurrence of recombination [73-78]. In some cases, $\mathrm{Cu}$ is mostly re-oxidized either from $\mathrm{Cu}$ (metal) to $\mathrm{Cu}^{+}$or from $\mathrm{Cu}^{2+}$ to $\mathrm{Cu}^{+}$after the photocatalytic reaction and this is usually obvious in the colour changes of the $\mathrm{Cu}$ doped photocatalysts by (usually to a darker colour) [74]. It has been proven from different reports that doping of $\mathrm{Cu}$ on $\mathrm{TiO}_{2}$ improves the photo-activity of $\mathrm{TiO}_{2}$ as the $\mathrm{Cu}$ metal acts as an electron trapping agent whilst maintaining the mobility of photoelectrons in the photocatalyst. Also, doping of $\mathrm{Cu}$ into $\mathrm{TiO}_{2}$ could lower its band gap due to the lower redox potential of copper ions thus improving its light absorption efficiency [32, 79]. Li et al 2016 reported that the impregnation of copper could improve the photo-efficiency and selectivity to produce methanol and ethanol. The increased photo-activity of $\mathrm{Cu} / \mathrm{TiO}_{2}$ is since the $\mathrm{Cu}$ ions act as electron trapping sites, improving interfacial charge transfer, enhancing charge separation at the Schottky barrier whilst maintaining the mobility of the photoelectrons. $\mathrm{Na}_{2} \mathrm{SO}_{3}$ was used 
as a hole scavenger in this report and stated that its presence facilitated the production of ethanol. One drawback with excess copper loading is reduced surface area and decreased photo-excitation capacity. Therefore, doping most noble metals into a semiconductor photocatalyst results in a reduction in its band gap, improvement in the visible light absorption and increase in the charge transfer rate hence boosting the photo-activity. However, due to the relationship between band gap engineering and reduction potential of the semiconductor and metal dopant two main metals $(\mathrm{Cu}$ and $\mathrm{Ag})$ perform better for photoreduction of $\mathrm{CO}_{2}$ to methanol.

\subsubsection{Non-metal doping}

Another type of $\mathrm{TiO}_{2}$ modified system is photocatalyst systems based on semiconductors doped with anions ( $\mathrm{C}, \mathrm{N}, \mathrm{S}, \mathrm{P}, \mathrm{B}$ etc.). The least reported non-metal doped with $\mathrm{TiO}_{2}$ for $\mathrm{CO}_{2}$ photoreduction is phosphorus however Wang et al 2016 reported the use of phosphorus doped $\mathrm{TiO}_{2}$ nanotubes. A high methanol yield of up to $860.4 \mu \mathrm{molg} / \mathrm{cat}$ was achieved from this work, Fig. 5. details results obtained from this work [80]. Anionic (nonmetal) doping introduces substitution of lattice oxygen of $\mathrm{TiO}_{2}$, transfer of occupied orbitals above the VB energy and narrowing the band gap energy hence fostering absorption of visible light. Anionic doping of nitrogen from previous research is seen to have the highest influence in narrowing band gap possibly due to its similarity in atomic size with oxygen, high stability and low ionization energy [81].

Nitrogen is a commonly used non-metal for semiconductor doping in diverse applications including photoreduction of $\mathrm{CO}_{2}$. Tsai et al demonstrated the importance of nitrogen doping in their work where they reported $\mathrm{N}$-doped $\mathrm{InTaO}_{4}$. In this work nitrogen doping was used to improve the light absorption of the photocatalyst by shifting its absorption band. It also helped to inhibit recombination of electron-hole pairs. They reported that doping 
with nitrogen resulted in a red shift in absorption wavelength of the material. Also, the band gap was narrowed allowing for parallel movements of absorption edges. It was possible to shorten the band gap by nitrogen doping because the energy of $\mathrm{N}^{2 \mathrm{p}}$ is higher than that of $\mathrm{O}^{2 \mathrm{p}}$. Hence, annealing the material in $\mathrm{NH}_{3}$ to achieve $\mathrm{N}$-doping was able to shift the absorption band and shorten the band gap. The yield of methanol was doubled when $\mathrm{InTaO}_{4}$ was doped with $\mathrm{N}$ compared to without it, this indicated the importance of nitrogen doping in the photocatalyst material [82]. Kumar et al also reported the photoreduction of $\mathrm{CO}_{2}$ to methanol under visible light using nitrogen doped graphene supported on copper complex. In this work the researchers also reported that $\mathrm{N}$-doping helped to reduce recombination during the photocatalytic process. When nitrogen was doped with graphene it was able to bind effectively with three carbon atoms by $\mathrm{sp}^{2}$ hybridization hence it was able to influence the distribution of charges within the carbon atoms. By combining its $\pi$-bonds with those from graphene, a very rich electron cloud was created. This caused a shift in the Fermi level resulting in a break of the graphene symmetry resulting in the creation of a CB and VB. Due to this, the N-doped graphene functioned as a semiconductor material. Another major advantage of N-doping in this work is the creation of multiple electron transfer through its $\pi$-bond interaction with graphene thereby providing multiple electrons for generation of methanol [83]. Although anionic (non-metal) doping of $\mathrm{TiO}_{2}$ can improve its photo-activity, some reports focus on its application for other processes. More reports can be gathered on its application in dye degradation, dye sensitized solar cells, oxygen/hydrogen evolution reaction (OER/HER), $\mathrm{CO}_{2}$ reduction to methane, hydrogen and other hydrocarbons. Different methods have been used for synthesis of N-doped semiconductor photocatalysts. Fig. 6. Exhibits different synthesis methods previously reported [84]. 


\subsubsection{Co-Metal doping}

Co-doping involves the doping of more than one metal on a semiconductor and this is useful for tuning the selectivity of reduction products from the process. As an example, common co-catalysts used for the $\mathrm{CO}_{2}$ photoreduction process are $\mathrm{Ag}$ and $\mathrm{Cu}$ whereas $\mathrm{Pt}$ and $\mathrm{Au}$ are more favourable for hydrogen production. Fig. 5 exhibits the photocatalytic reduction mechanism of $\mathrm{CO}_{2}$ to methanol using $\mathrm{TiO}_{2}$ modified with two different metal dopants. As depicted in Fig. 5, compared to Fig. 4 both reduction $\left(\mathrm{CO}_{2}\right.$ to hydrocarbon fuels) and oxidation reaction take place on two different doped metal atoms. This means photo-generated electrons are transferred from the $\mathrm{VB}$ of $\mathrm{TiO}_{2}$ to its $\mathrm{CB}$ then to the $\mathrm{CB}$ of the heteroatom while holes are transferred to the VB.

Different metals have been reported as viable co-catalysts for two main purposes; to extend the VLR efficiency of $\mathrm{TiO}_{2}$ and accomplish improved quantum efficiency and yield by decreasing recombination of electron-hole species[85]. The choice of co-dopants and their percentage is of outmost importance because co-doping of metals leads to competition for functionality. Kavil et al recently showed the effect of co-doping by using $\mathrm{Cu}-\mathrm{C}$ as co-dopants for $\mathrm{TiO}_{2}$ [86]. Fig. 7. Shows the mechanism of $\mathrm{CO}_{2}$ photoreduction for $\mathrm{Cu}-\mathrm{C} / \mathrm{TiO}_{2}$ under $\mathrm{UV}$ light (a) Time dependence study of methanol yield for $\mathrm{TiO}_{2}$ and $\mathrm{Cu}-\mathrm{C} / \mathrm{TiO}_{2}$ photocatalysts under UV light (b). It is common knowledge that carbon and nitrogen are highly conductive and electron rich hence they are used for modification of materials in applications such as energy storage materials e.g. batteries and energy releasing reactions such as oxygen and hydrogen evolution reactions. However, carbon is seldom used for modifying photocatalyst materials. In this work they synthesized the $\mathrm{Cu}-\mathrm{C} / \mathrm{TiO}_{2}$ photocatalysts by sol-gel method, used $\mathrm{NaOH}$ as the reductant and a UV lamp of $365 \mathrm{~nm}$ wavelength and natural sunlight were used as the light source. A high methanol yield of $2593 \mu \mathrm{mol} / \mathrm{g}$ was obtained after $5 \mathrm{~h}$ reaction and the $\mathrm{Cu}-\mathrm{C} / \mathrm{TiO}_{2}$ photocatalyst performed better than $\mathrm{TiO}_{2}(\mathrm{P} 25)$ and $\mathrm{C} / \mathrm{TiO}_{2}$ though that of the 
latter was higher than the former. Each constituent of the photocatalyst provided different benefits to the overall system. Recombination of holes and electrons was suppressed by $\mathrm{Cu}$ due to its property as an electron trapping agent, $\mathrm{C}$ helped to reduce the optical band gap energy of $\mathrm{TiO}_{2}$ while $\mathrm{TiO}_{2}$ served as the basic semiconductor photocatalyst. Contact between $\mathrm{TiO}_{2}$ and $\mathrm{Cu}$ encouraged charge redistribution through the photocatalyst. Therefore, separation of electron-hole species was enhanced due to rapid migration of photo-generated electrons. It is noteworthy to mention that $\mathrm{Cu}^{2+}$ was used in this work and it is known to be a very good oxidation state of $\mathrm{Cu}$ to function as a dopant. Its unfilled $3 \mathrm{~d}$ shell electrons can be easily trapped onto surface of $\mathrm{TiO}_{2}$. The photo-energized conduction band electrons $\left(e_{c b}^{-}\right)$will be attracted by $\mathrm{Cu}^{2+}$ and reduced to $\mathrm{Cu}$ species. Electrons on the $\mathrm{Cu}^{+}$species can then be consumed as a result of the decline in hydrogen radical $\mathrm{H} \cdot$ production by $\mathrm{H}^{+}$therefore $\mathrm{Cu}^{+}$ can be re-oxidized back to $\mathrm{Cu}^{2+}$. Repetition of this cycle during photoreaction can hence inhibit recombination in the reaction. Based on the mechanism of methanol production from $\mathrm{CO}_{2}$ proposed by Kakumoto, the Authors suggested a sequence of reactions to form methanol. Firstly, adsorption of $\mathrm{CO}_{2}$ on $\mathrm{Cu}$, attack of $\mathrm{CO}_{2}$ by $\mathrm{H}$ atom adsorbed on $\mathrm{Cu}$ resulting in formate intermediate formation. Further attack of $\mathrm{C}-\mathrm{O}$ bond of formate species by $\mathrm{H}$ atom resulted in $\mathrm{HCOH}$ intermediate formation on $\mathrm{Cu}$ and, attack of $\mathrm{HCOH}$ intermediate specie by $\mathrm{H}$ atoms on $\mathrm{TiO}_{2}$ to yield $\mathrm{CH}_{3} \mathrm{O}$ intermediate and finally methanol formation.

\subsubsection{Modification using Metal Oxides}

Metal oxides have also been used for doping pure $\mathrm{TiO}_{2}$ to obtain photocatalysts of superior photo-activity due to the improved charge separation [87-89], light absorption [8890], structural properties $[89,90]$ and surface chemistry $[87,88,90]$. At the heterojunction of the $\mathrm{MO}$ and $\mathrm{TiO}_{2}$ charge separation is achieved and this creates a separation of redox reactions which prevents back and side reactions benefiting the yield of the product from the 
photoreduction of $\mathrm{CO}_{2}$. This is because if the $\mathrm{MO}$ doped has a smaller band gap compared to $\mathrm{TiO}_{2}$ it improves the light absorption capacity of the composite formed. However, the improved light absorption is dependent on whether or not the VBs and CBs are well matched for simultaneous charge separation[91]. A very good example is Slamet et. al,. 2005's work on photocatalytic reduction of $\mathrm{CO}_{2}$ on copper doped $\mathrm{TiO}_{2}$. They synthesized different species of copper $\left(\mathrm{Cu}^{\mathrm{o}}, \mathrm{Cu}^{\mathrm{I}}, \mathrm{Cu}^{\mathrm{II}}\right)$ by improved impregnation method. CuO was the most active dopant compared with other copper species synthesized. Since the band gap of the synthesized copper-loaded catalysts were smaller than that of $\mathrm{TiO}_{2}$ the photon energy needed to excite electrons and holes would not be too high. Furthermore, it can increase the activity of $\mathrm{TiO}_{2}$. They reported methanol as the product of the photoreduction process and $\mathrm{CuO}$ gave the highest yield although $\mathrm{Cu}_{2} \mathrm{O}$ showed very promising result [92]. $\mathrm{Cu}_{2} \mathrm{O}$ is one of the most reported MO dopants due to its band gap of 2.0-2.2 eV which effectively absorbs visible light and its VB and CB well matched to shorten distance from the bulk to surface when using $\mathrm{TiO}_{2}$ and $\mathrm{Cu}_{2} \mathrm{O}$ nanoparticles [85]. Nasution et al also researched on photoreduction of $\mathrm{CO}_{2}$ to methanol using 3\% $\mathrm{CuO}$ doped $\mathrm{TiO}_{2}$ synthesized by improved impregnation method [93]. In the research, $\mathrm{CO}_{2}$ saturated $\mathrm{KHCO}_{3}(1 \mathrm{M} 300 \mathrm{~mL}$ solution) was used and a $10 \mathrm{~W}$ UV black light lamp with a wavelength of $415-700 \mathrm{~nm}$ and $2.45 \mathrm{~mW} \mathrm{~cm}{ }^{2}$ was the light source. The slurry type photocatalytic reactor consisted of a horizontal stainless-steel vessel with an inner diameter and height of the vessel 140 and $50 \mathrm{~mm}$, respectively having a plate cover at the top of the vessel made of Pyrex. They reported methanol product of 442.5 and $19.23 \mu$ molh $^{-1}$ per g catalyst [93].

\subsubsection{Modification by formation of nanomaterials}

The nanostructured composites have been widely researched due to their viable benefits. Nano-structured photocatalysts offer various advantages such as high adsorption 
surface area, faster diffusion rate, inhibition of electron-hole pair recombination and higher surface to volume ratios [94]. Several materials have been synthesized in nanosizes such as nano-rods, nanofibers, nanotubes, nanowires and nano-strings and ribbons. Unique nanostructured composite and heterostructured materials have also been synthesized e.g. coreshell, hollow, multi-shell and yolk-shell structures. These different nanostructured materials can provide features which are able to improve the efficiency of the photocatalyst material. These features cause the photocatalyst to experience; greater adsorption capacity, higher surface to volume ratios, fast diffusion rate and inhibition of electron-pair recombination. As a result of their unique morphology electron pathways are well-defined and interconnected hence their transport is rapid and wider. Also, the unique structures allow for effective separation of electron-hole pairs and this means they help to inhibit recombination in these materials.

In the investigation of Wang et al on $\mathrm{Pt}_{-} \mathrm{TiO}_{2}$ nanowires, they reported nanowires with graphene-like properties were more effective for separation of electron hole pairs hence they showed enhanced photo-activity. [95]. Carbon nanotubes and 1D nanowires demonstrated outstanding results due to their spatial electronic configuration. Single walled and multi walled carbon nanotubes doped with $\mathrm{TiO}_{2}$ also recorded enhanced photocatalytic activity [35]. The large surface areas and inhibition of recombination boosted the yield in the photoreduction of $\mathrm{CO}_{2}$ to methanol. Despite the advantages of these unique structures only a few literatures exist on the design of unique structures like hollow, core-shell, yolk-shell and multi-shell morphologies for $\mathrm{CO}_{2}$ photoreduction. However, a few works exist which demonstrate the importance of these unique nanostructured materials for $\mathrm{CO}_{2}$ photoreduction. Examples include; Dai et al (flower-like), Hefeng et al (hollow structure) Tsai et al (core-shell structure), Junior et al and Ijaz et al (rod-like structure) [78, 82, 96-98]. 
One of the outstanding works on $\mathrm{CO}_{2}$ photoreduction using core-shell structure is that of Tsai et al, a methanol yield of over $300 \mathrm{~mol} / \mathrm{g}$. cat. was obtained [82]. These unique structures particularly core-shell structures provide several advantages in photocatalysis. As an example, encapsulating a metal $(\mathrm{Cu})$ into a semiconductor like $\mathrm{TiO}_{2}$ provides the semiconductor with stability inhibiting aggregation, corrosion and damage of its structure. Likewise, the low-lying fermi energy level of the metal provides an electron sink/reservoir thereby extending the lifetime of photo-generated charge carriers, boosting product yield and efficiency of the process. Also, the unique core/yolk shell structure avails close metalsemiconductor contact thereby improving the process of interfacial charge transfer [99]. It is obvious that more work needs to be done in the design and synthesis of nanostructured materials with unique morphologies for improved $\mathrm{CO}_{2}$ photoreduction. Two limitations affect this approach: complexity of synthesis and use of toxic/dangerous chemicals. However, simpler and green chemicals for effective synthesis can be sourced.

Particles size is an important property which dictates the reaction pathway of materials. By a phenomenon known as quantum size effect, nanosized $\mathrm{TiO}_{2}$ particles showed an increase in its CB with a corresponding decrease in VB [100]. The understanding of this phenomenon came with the knowledge that decreasing particle size resulted in changes in the recombination rates at the surface. A decrease in particle size leads to a decrease in volume recombination which in turn leads to improved photonic efficiency as a result of improved interfacial charge transfer rate. Since particle size affects the adsorption rate of $\mathrm{CO}_{2}$ and these affected the band gap and recombination rate, it is evident that synthesis of nanostructured materials with unique morphology is one way to achieve better product yield in photoreduction of $\mathrm{CO}_{2}[101]$.

The importance of crystallite size to performance and photo-activity of photocatalysts was long demonstrated by the work of Koci and Obalova where they studied the effect of $\mathrm{TiO}_{2}$ 
particle size on the band gap and yield of methanol. In this work they concluded that higher methanol and methane yield was obtained as particle size reduced. The optimal particle size reported was $14 \mathrm{~nm}$ and below this size photo-activity of the photocatalyst began to decline. They highlighted that competition for surface area, light absorption efficiency and chargecarrier dynamics accounted for the observed optimum particle size [100]. From this work it was established that particle indeed affects the photo-activity of a photocatalyst material. Therefore, keeping the morphology and structure of the material in mind, particle size is also a very important part of the material used for $\mathrm{CO}_{2}$ photoreduction. Fig. 8. Shows the effect of $\mathrm{TiO}_{2}$ particle size on band gap and product yield obtained from this work. Nanostructured materials are the way forward for photocatalytic reactions and particularly photoreduction of $\mathrm{CO}_{2}$.

\subsubsection{Modification by Sensitization}

Surface sensitization increases the efficiency of the excitation processes and expands the usable light wavelength of the photocatalyst by excitation. The sensitizers can enhance the visible light absorption of a semiconductor [102]. The semiconductor serves primarily as the charge carrier, rather than the source of electrons and holes photo generated electrons and is very fast. Dye sensitizers are one of the most widely employed sensitizers. Fig. 9. Illustrates the photoreduction scheme of $\mathrm{CO}_{2}$ to methanol using dye sensitized $\mathrm{TiO}_{2}$ photocatalyst. In this system the dye and semiconductor $\left(\mathrm{TiO}_{2}\right)$ assume different responsibilities in that $\mathrm{TiO}_{2}$ serves as the electron acceptor while the dye bears the role of light harvester. In a typical situation, like other photocatalytic systems it begins with photo-excitation of electrons from the highest occupied molecular orbital (HOMO) of the dye to its lowest unoccupied molecular orbital (LUMO) followed by transference of photo-generated electrons from the LUMO of the dye to the $\mathrm{CB}$ of $\mathrm{TiO}_{2}$ and this is then used up by the reactant $\mathrm{CO}_{2}$ for reductive conversion 
of $\mathrm{CO}_{2}$ to hydrocarbon fuels. A benefit of this process is the possibility of recycling the oxidized dye through oxidation of $\mathrm{H}_{2} \mathrm{O}$. Photoelectrons are provided by a photosensitive dye that is in contact with the semiconductor material and charge separation occurs at the surfaces between the dye, semiconductor, and an electrolyte. Surface sensitization through chemisorbed or physiosorbed dyes increase the excitation process and expands the usable light wavelength through excitation. In dye photosensitization, if the oxidative energy level of the excited dye is more electronegative than the $\mathrm{CB}$ of the semiconductor e.g. $\mathrm{TiO}_{2}$, electrons produced in $\mathrm{CB}$ of the dye sensitizer are transferred to the $\mathrm{CB}$ of $\mathrm{TiO}_{2}$ during visible light irradiation. The efficiency of this electron transfer process is dependent upon the lower unoccupied molecular orbital and the conduction band edge of the $\mathrm{TiO}_{2}$ or other semiconductor used [103].

Several research works have used dye sensitizers for $\mathrm{CO}_{2}$ reduction [104]. They have been mostly used for $\mathrm{CO}_{2}$ reduction to methane and other hydrocarbon fuels, but the efficiency and conversion are minimal. Thus, further research is required. Other types of sensitizers include coupling semiconductors e.g. $\mathrm{AgBr} / \mathrm{TiO}_{2}$, quantum dots e.g. CdSe QDs and phthalocyanine oxide derived photocatalysts and novel sensitizers [105]. The quantum dots sensitized photocatalysts have been researched in the photoreduction of $\mathrm{CO}_{2}$ to methanol with commendable results. QDs possess outstanding electronic as well as optical properties which distinguish them from others. The QDs exhibit high absorption capacity for light [106], their band gaps can be corrected easily by simply modifying their size [107]. This makes it easy to align their band gap to that of the solar spectrum. The structure of their electrons can be easily tuned and used to prepare heterostructures having specific band alignment. Thus, electronhole pairs which causes recombination [108] are maximally separated. Also, optimizing their energetics for optimum light absorption will be made easy and their redox chemistry will be better. Another advantage QDs have is that if synthesized with highly advanced method, 
materials whose structures and properties can be controlled for specific applications can be obtained. The QDs are also nanometre in measurement meaning they naturally possess large surface area which is key for effective adsorption and uptake in catalysis. It is possible that multiple electron generation can efficiently take place in QDs and this means enhanced photocatalysis is possible [109]. QDs which have band gaps in the near infrared region (PbS and $\mathrm{PbSe}$ ) [106] demonstrate strong electronic interaction with catalytically active $\mathrm{TiO}_{2}$ under visible light [110]. The unique size of the quantum dots which influences characteristics such as intrinsic optical and electrical behaviour distinguishes the dye sensitized $\mathrm{TiO}_{2}$ from the normal $\mathrm{TiO}_{2}$. Generally chalcogenide metals inclusive of $\mathrm{CdS}$ and $\mathrm{ZnS}$ are used with semiconductors like $\mathrm{TiO}_{2}$ to propagate photon transformation of $\mathrm{CO}_{2}$ to hydrocarbon fuels. Small sized QDs inject electrons swiftly to the conduction band edge of $\mathrm{TiO}_{2}$ and large-sized QDs cover the visible region [111]. The metal phthalocyanines possess an unusual semiconductivity and chemical stability which makes them relevant in the application of photoreduction of $\mathrm{CO}_{2}$. Just like the quantum dots, when photo-excited under visible light they can emit electrons to the conduction band of $\mathrm{TiO}_{2}$. This improves the electron hole separation and reducing band gap for photocatalytic efficiency, selectivity and higher yield of specific hydrocarbon fuels [112].

\subsubsection{Modification by Formation of Heterostructures}

The formation of heterostructures is arguably the most effective method of modifying the properties of a photocatalyst. When properly matched, the individual semiconductors demonstrate a mutualistic relationship in that the heterostructure combines the individual properties of each semiconductor which results in a material with a photo-activity that is greater than that of each photocatalyst. A schematic diagram illustrating photoreduction of $\mathrm{CO}_{2}$ to methanol through a heterojunction in a composite catalyst is depicted in Fig. 10 [113]. 
Heterostructure is formed by the combination of two semiconductors which have complementary properties of making the heterostructure perform better than the individual materials. Like all pure photocatalysts, the photoreaction in an heterostructure begins with photo-activation and excitation of the individual materials forming the heterostructure. When irradiated and photo-activation occurs, photo-generated electrons move from the $\mathrm{CB}$ of semiconductor $\mathrm{B}$ and transfer to that of $\mathrm{A}$. The determination of origin and destination of photo-generated electrons depends on the band engineering of the heterostructure [27]. As a principle, photo-generated electrons generally move from a semiconductor with a higher $\mathrm{CB}$ to that with lower $\mathrm{CB}$ as the energy requirement for such a transition is not as high as that required for the opposite. The photo-generated electrons transferred to A can then be used at the surface for reduction reaction $\left(\mathrm{CO}_{2}\right.$ to methanol). Simultaneously, as this process occurs, photo-generated holes migrate from the $\mathrm{VB}$ of $\mathrm{A}$ to that of $\mathrm{B}$ i.e. in the opposite of the electrons. The photo-generated holes which are transferred are likewise used for reactions at the surface but in this case a water reaction [30].

Formation of heterostructures generally improve light absorption capacity, enhance textural and morphological properties, foster separation of electron-hole pairs and increase efficiency of $\mathrm{CO}_{2}$ photoreduction. Separation of charges is usually accomplished by transference of photo-generated electrons from the semiconductor with higher $\mathrm{CB}$ to that with lower $\mathrm{CB}$ and migration of holes from semiconductor with lower VB to higher VB. This was observed by Wang et al., when $\mathrm{Cu}_{2} \mathrm{O} / \mathrm{TiO}_{2}$ nanotube was used to photo-reduce $\mathrm{CO}_{2}$ to methanol under UV-visible light. Since $\mathrm{TiO}_{2}$ had a lower $\mathrm{CB}$ of -0.5 while $\mathrm{Cu}_{2} \mathrm{O}$ had a $\mathrm{CB}$ of about -1.5, flow of electrons was from the $\mathrm{CB}$ of $\mathrm{Cu}_{2} \mathrm{O}$ to that of $\mathrm{TiO}_{2}$ while flow of holes was from the $\mathrm{VB}$ of $\mathrm{TiO}_{2}$ to that of $\mathrm{Cu}_{2} \mathrm{O}$. This was the reason for improved photo-activity and stability since charge separation was facilitated [30, 114]. The choice of individual semiconductors used for a heterostructure dictates its photo-activity and effectiveness. For 
example, using a VLR photocatalyst like $\mathrm{CeF}_{3}$ with $\mathrm{TiO}_{2}$ can produce an heterostructure that is active both in the UV and visible region [115]. Similarly, the use of materials with $d-\pi$ or $\pi$ - $\pi$ overlapping such as CNTs, nanostructured polymeric materials can improve charge separation as these $\pi$ interactions create a passage for photo-generated electrons [116-118].

Another modification method employed to improve the effectiveness of $\mathrm{TiO}_{2}$ as a photocatalyst for $\mathrm{CO}_{2}$ photoreduction is by creating defects in the structure. Defect chemistry is a very effective way to modify the intrinsic properties of a material thereby improving the rate of electron and ion transport within its structure [119]. Particularly, the research into engineering defects in metal oxides have gained massive attention over the years [120]. Anatase $\mathrm{TiO}_{2}$ is highly susceptible to defect e.g. oxygen vacancies [121] or formation of amorphous layers at the surface [122]. These defects can be created by; calcination [123], high energy ball milling [124], microwave/ultrasonic irradiation [125], doping [126], hydrogenation process [127], plasma treatment [128], the use of strong reducing agents such as sodium borohydride [129] and electrochemical reduction [130]. The effect and study of defects on the structure of the material can be observed by analysing the surface chemistry of the material using high powered microscope [131] or by density functional theory (DFT) prediction. This was reported by Liu et al., who studied the mechanism of $\mathrm{CO}_{2}$ photoreduction of $\mathrm{CH}_{3} \mathrm{OH}$ on the (101) surface of Anatase $\mathrm{TiO}_{2}$. In their study they created defects via oxygen vacancy on the surface of the $\mathrm{TiO}_{2}$ structure and they investigated the reaction pathway for a one-electron $\mathrm{CO}_{2}$ photoreduction process to generate $\mathrm{CH}_{4}$ and $\mathrm{CH}_{3} \mathrm{OH}$ using DFT. This study proved that oxygen vacancies facilitated the reaction rapidly when compared to pristine/bulk $\mathrm{TiO}_{2}$ because the adsorption energy of $\mathrm{CO}_{2}$ molecules on the surface of the defected structure was greater. Furthermore, the common problem of reaction intermediates hindering production of desired products was limited on the defected structure. Since $\mathrm{CO}_{2}$ photoreduction is often a multi-directional pathway reaction, they reported that the feasible 
progression from this work was; through the $\mathrm{CO}$ species on the surface, to $\mathrm{CHO}, \mathrm{CHOH}$, $\mathrm{CH}_{2} \mathrm{OH}$ or $\mathrm{CHO}, \mathrm{CH}_{2} \mathrm{O}$ and $\mathrm{CH}_{3} \mathrm{O}$ which leads to production of $\mathrm{CH}_{4}$ and $\mathrm{CH}_{3} \mathrm{OH}$ [132]. Despite the successful results obtained, they however identified that the energy barrier to be overcome for each step of the reaction pathway were very high and there was a need to decrease the activation energies which would further accelerate the reaction rate and improve product yield.

\subsubsection{Metal-Ligand Charge Transfer}

The focus of research in photocatalysis and photoelectrochemical systems have been development of different ways to circumvent the obstacle of recombination. Two approaches have been used over the years and these are: - band engineering and synthesis of nanomaterials [133]. The first approach has been discussed so far. The second approach focuses on material design through synthesis of 1D, 2D and 3D materials, sub-1 nm ultrathin material, different morphologies (rod, sphere, single, multi, hollow and core-shell structures, carbon nanodots etc). This approach changes or modifies the pore size, surface area, mass transport and the pathway excitons use in approaching the surface of the semiconductor hence its interfacial charge transfer can be improved $[134,135]$. Interfacial charge transfer can be regarded as the effective and efficient transport of excitons through the interfaces in a semiconductor. The interfacial charge transfer can be considered for a semiconductor-heteroatom (doped material), a semiconductor-semiconductor (composite and heterostructured materials), and Ligand-semiconductor material. Throughout this review the first two (doped material and composite/heterostructured material) have been extensively discussed because several works have been reported on their application for $\mathrm{CO}_{2}$ photoreduction. This section provides a brief discussion on the principle behind reduction of $\mathrm{CO}_{2}$ to useful fuels using homogeneous catalytic systems with focus Metal-Ligand Charge Transfer (MLCT) [71]. 
Photoreduction of $\mathrm{CO}_{2}$ have been explored using either of two categories of catalytic systems; heterogeneous catalytic systems (involving nanoparticles of semiconductors) and homogeneous metal complexes also known as molecular or ligand metal complexes. The interfacial charge transfer in the molecular or ligand metal complexes are the focus of this section. The use of molecular or ligand metal complexes for catalytic reactions provide a mechanistic edge over the heterogeneous catalytic systems because they are able to effectively reduce/convert $\mathrm{CO}_{2}$ to useful chemicals by a multi-electron process due to the transition metal in their complexes $[136,137]$. Their ability to store electrons in vacant $\pi^{*}$ orbitals make it possible for them to execute multi-electron reduction of an acceptor $\left(\mathrm{CO}_{2}\right)$. This network of $\pi$ systems also make it possible for such ligands to shift their light absorption to regions of lower energy thereby improving their absorption of light. Also, some complexes can generate bimetallic systems due to the presence of their bidentate ligand which possess additional binding sites. This bimetallic system means their transition metal can function as extra light absorbers and the extra binding sites can allow for interaction with more acceptors [138]. The most commonly used complexes (in no particular order) contain transition metals such as Co [139], Ni [140], Re [141], Ru [142], Fe [136], Mn [143], Pt , Pd etc. Though most of these noble metal complexes have been deployed for $\mathrm{CO}$ production from $\mathrm{CO}_{2}[136,140,141]$, some of them have been reported to work successfully in production of methanol and formate e.g. Ru and Re. The homogeneous catalytic systems would usually consist of a photosensitizer (light harvester) and the catalytic sites (one for reduction and the other for oxidation).

Typically, the process for photocatalytic systems begin with irradiation of light, absorption of photons by the photosensitizer and photo-excitation. Photo-excited electron migrates from the orbitals of the transition metal ion to the empty orbital of the ligand hence formation of a singlet metal to ligand charge transfer $\left({ }^{1} \mathrm{MLCT}\right)$ occurs [144]. Migration of the photo-excited electron creates a vacuum (hole), if a sacrificial electron donor such as TEOA 
(triethanolamine) or ascorbate is used in the system this hole can be rapidly filled by electrontransfer from them. This process is known as reductive quenching of the photo-excited state. This leads to inter-system crossing (ISC) and transfer of the electrons to the triplet excited state $\left({ }^{3} \mathrm{MLCT}\right)$. This triplet excited state represents the reductive site and compared to the ground state it possesses several redox properties. The reduced complex at this ${ }^{3}$ MLCT state will possess a reduction potential close to that of an aromatic radical say about $1.02 \mathrm{~V}$ vs NHE as the case of $\left[\mathrm{Ru}(\mathrm{bpy})_{3}\right]^{+}$. Having such a potential the complex is more suited to reduce protons to hydrocarbon products such as $\mathrm{CO}$ and methanol. In most cases the ${ }^{3} \mathrm{MLCT}$ is only stable for microseconds and interaction with the electron produced by the oxidative site causes the ground state of the one-electron reduced specie to be formed. With the production of oneelectron reduced specie an electron can then be transferred to the reductive site so that the $\mathrm{d}^{6}$ neutral ground state of the photosensitizer is recovered $[71,140]$. Fig. 11. Illustrates the basic principle of photo-redox reactions in homogeneous catalytic systems.

In a nutshell, the process occurs as a cycle which begins with photo-excitation and absorption, electron-transfer and redox reaction then deactivation and returning to the initial state. Deactivation of decay of the excited state generally occurs by one of two non-reactive pathways; emission of a photon or vibrational relaxation. The former is a slow radiative process known as luminescence while the latter is a faster non-radiative decay process. The pivotal issue in catalytic systems involving Ligand-Metal Complexes is ways to extend the lifetime of the excited state as this means more time for interaction with the acceptor $\left(\mathrm{CO}_{2}\right)$ and the more products that can be formed. Fig. 12. Shows the electronic pathway of interfacial charge transfer in the redox reaction of a ligand based photocatalytic system.

Though several factors dictate the lifetime of the excited state, the type of photosensitizer or chromophores used is crucial as they all absorb at different region of the solar spectrum. Some of them are better absorbers in the visible light spectrum while others 
are more active in the UV spectrum. Transition metal complexes of ruthenium polypyridyl are an example of chromophores which absorb very well in the visible region hence they are preferable for photo-redox reactions. A number of reports have been made on photoreduction of $\mathrm{CO}_{2}$ to methanol using Ruthenium complex and the first reported work was by MacDonnell et al [145]. They reported photoreduction of $\mathrm{CO}_{2}$ to methanol and formate using a pyridinebased complex with $\left[\mathrm{Ru}(\mathrm{phen})_{3}\right]^{2+}$ as the chromophore while the sacrificial electron donor was ascorbate. The turnover for formate and methanol after $1 \mathrm{hr}$. were 0.025 and $1.1 \times 10^{-4}$ respectively, due to degradation of the chromophore the system became inactive after $6 \mathrm{hr}$.

Contrary to previous reports on pyridine based systems they reported addition of $\mathrm{Pt}$ yielded no methanol in their system [145]. In 2014, MacDonnell et al [142] used a system combining $\left[\mathrm{Ru}(\mathrm{phen})_{3}\right]^{2+}$ and pyridine for photoreduction of $\mathrm{CO}_{2}$ to methanol, formate and formaldehyde using a mixed solvent of water and DMF and with TEA as the sacrificial reductant. They synthesized two forms of the Ruthenium complex chromophore; $\left(\left[\operatorname{Ru}(\operatorname{phen})_{2}(\operatorname{ptpb} \alpha)\right]^{2+}(\operatorname{Ru} \alpha)\right.$ and $\left[\operatorname{Ru}(\operatorname{phen})_{2}(\operatorname{ptpb} \beta)\right]^{2+}(\operatorname{Ru} \beta)$ which functioned as electrocatalysts and photocatalysts for $\mathrm{CO}_{2}$ photoreduction. The selectivity and choice of product obtained using the chromophore $(\mathrm{Ru} \beta)$ was different for different solvents [142]. The higher solubility of $\mathrm{CO}_{2}$ in $\mathrm{DMF}$ and the fact that the photo-excited state of the complexes can be improved in mixed solvent systems of water and aprotic solvent also contributed to the efficiency of the system. In aqueous solvents, the complexes tend to lose their photochemical activity which is why water is seldom used as a medium for this systems though several researchers have tried to use water with no success [139]. These $\left[\operatorname{Ru}(\operatorname{phen})_{3}\right]^{2+}$ based complexes showed better methanol selectivity than formate and their activity was higher than previously reported but the use of DMF was a concern hence the search for better aqueous systems was pertinent. 
One of the limitations of homogeneous systems is the fact that as the name implies, the catalysts are homogeneous and are mostly rare-earth metals. This means; unlike heterostructures they would lack some sort of thermal and mechanical support and stability, sustainability would be difficult because they are expensive, recovery of the catalyst will be a challenge hence releasing it to the environment will be harmful. Suman et al approached this problem by attaching the complex to graphene due to its excellent properties. They reported the photoreduction of $\mathrm{CO}_{2}$ to methanol in a water-DMF solution using TEA as the reductive quencher but using ruthenium trinuclear polyazine complex immobilized on graphene in phenanthroline $(\mathrm{Ru}-\mathrm{phen}-\mathrm{GO})$ as the chromophore. This work reported one of the highest yield of methanol (3977.57 $\mu$ molgcat $^{-1}$ after $48 \mathrm{hr}$. irradiation) from a homogeneous catalytic system [146]. Methanol is a very functional chemical that can be obtained from photoreduction of $\mathrm{CO}_{2}$ [147]. Formic acid is another resourceful product from $\mathrm{CO}_{2}$ photoreduction due to the variety of functions it serves in the chemical industry. There are several reports on the successful photoconversion of $\mathrm{CO}_{2}$ to formic acid using homogeneous catalytic systems though majority of them deal with metal organic frameworks (MOFs). One of the notable works on the application of homogeneous catalyst system particularly ruthenium complex is that of Osamu et al.[148]. They reported the use of Ru (II) multinuclear complexes for $\mathrm{CO}_{2}$ photoreduction however the high turnover frequency (671) obtained is what distinguished the work. Two different $\mathrm{Ru}(\mathrm{II})$ complexes $\left[\mathrm{Ru}(\mathrm{dmb})_{n}(\mathrm{BL})_{3-\mathrm{n}}\right]^{2+}$ and $\left[\mathrm{Ru}(\mathrm{dmb})_{m}(\mathrm{BL})_{2-\mathrm{m}}(\mathrm{CO})_{2}\right]^{2+}$ were used as photosensitizer and catalyst, respectively. As one of the first works to report the successful photoreduction of $\mathrm{CO}_{2}$ to formic acid using molecular photocatalysts, the principle behind the success of this work is sets the tone for several other works in this field. The first important finding was the excited electron of Ru (II) in its ${ }^{3} \mathrm{MLCT}$ was inserted in the bridging ligand. Another breakthrough for this work was instead of using a conjugated bridging ligand as previous works did, a non-conjugated bridging ligand was 
used. The reason for this was because the use of a conjugated bridging ligand would lead to a decrease in the reducing power of the catalyst.

The photoreduction process occurred via two important steps: reduction of the $\left[\mathrm{Ru}(\mathrm{dmb})_{n}(\mathrm{BL})_{3-\mathrm{n}}\right]^{2+}$ by a $\mathrm{NADH}$ modelled compound and transfer of electrons to $\left[\mathrm{Ru}(\mathrm{dmb})_{m}(\mathrm{BL})_{2-\mathrm{m}}(\mathrm{CO})_{2}\right]^{2+}[148]$. In 2015 Seth et al also successfully reduced $\mathrm{CO}_{2}$ to formic acid using a MOF (UiO-66 UiO - University of Oslo) having Cr (III) and Ga (III) metal sites with 1-benzyl-1,4-dihydronicotinamide (BNAH $\left.-\mathrm{C}_{13} \mathrm{H}_{14} \mathrm{~N}_{2} \mathrm{O}\right)$ and TEA as sacrificial reductants. The synthesis pathway for this photocatalyst is represented in Fig. 13. In this synthesis, a post synthetic method was used along with (catbdc, 2, 3-dihydroxyterephthalic acid (an organic linker) was used to synthesize the actual ligand to be used (UiO-66-CAT). Finally, the metals (Ga (III) and Cr (III) were incorporated into the MOF in order to foster electron transfer while the organic linker was responsible for the visible light absorption of the complex. Their report shows Cr (III) gave a much better TON than using Ga (III) owing to the structure of the former [149]. They also reported the use of a mixed metal and mixed ligand MOF - UiO-66-derivative $\left(\mathrm{Zr}_{4.3} \mathrm{Ti}_{1.7} \mathrm{O}_{4}(\mathrm{OH})_{4}\left(\mathrm{C}_{8} \mathrm{H}_{7} \mathrm{O}_{4} \mathrm{~N}\right)_{5.17}\left(\mathrm{C}_{8} \mathrm{H}_{8} \mathrm{O}_{4} \mathrm{~N}_{2}\right)_{0.83}\right.$ and $\left.{ }^{1}(\mathrm{Zr} / \mathrm{Ti})\right)$ for $\mathrm{CO}_{2}$ photoreduction to formic acid. Like their first report, post synthetic exchange (PSE) was used for synthesis of the complex and BNAH and TEOA were used as sacrificial reductant and sacrificial base. After 13 hours of irradiation, several other products $\left({ }^{13} \mathrm{CO}_{2}\right.$, $\left.{ }^{13} \mathrm{CO}_{3}{ }^{2-}, \mathrm{H}^{13} \mathrm{COO}^{-}, \mathrm{H}^{13} \mathrm{CO}_{3}{ }^{2-}\right)$ were detected by $\mathrm{NMR}$ and the major product was formic acid [137]. In summary, ligand based catalytic systems have proven to be an alternative route to photoreduction of $\mathrm{CO}_{2}$ to useful hydrocarbon fuels such as carbon monoxide, methanol and formic acid with high TON and good selectivity. However more research is still required for it to be up to par with conventional heterogeneous semiconductor based catalytic systems and obviously a long way before practical application can be achieved. Table 2. Lists previous researches on photoreduction of $\mathrm{CO}_{2}$ to methanol using $\mathrm{TiO}_{2}$ based photocatalysts. 


\subsection{Substitutes for $\mathrm{TiO}_{2}$ based photocatalysts for $\mathrm{CO}_{2}$ photoreduction}

Although $\mathrm{TiO}_{2}$ is a widely researched photocatalyst which possesses several properties that makes it a viable photocatalyst for commercial application, it is still limited by its wide band-gap. Hence, several alternative photocatalysts have been researched and are still been discovered by scientists. These include metal oxides, mixed metal oxides, graphene-based composites, sulphides, nitrides, and Metal Organic Frameworks (MOF) [167]. These photocatalysts possess enhanced properties better or equivalent to that of $\mathrm{TiO}_{2}$ complimenting the limitations of $\mathrm{TiO}_{2}$. Most of these photocatalytic materials have smaller band gap, matching valence and or conductance band, excellent physical, structural, crystallographic properties and better surface chemistry potentials. Although the materials still have some limitations, it is still increasingly being researched and used for $\mathrm{CO}_{2}$ photoreduction. Some of these non- $\mathrm{TiO}_{2}$ based catalysts have shown positive results in the photoreduction of $\mathrm{CO}_{2}$ to methanol specifically and the results are quite commendable compared to $\mathrm{TiO}_{2}$. For example, a methanol yield rate of $162,127.5$ and $63.5 \mu \mathrm{mol} \mathrm{g}{ }^{-1} \mathrm{~h}^{-1}$ was obtained for $\mathrm{Ni}-\mathrm{NiO} / \mathrm{InTaO}_{4}-\mathrm{N}$ and $\mathrm{InTaO}_{4}$, respectively when Tsai et. al,. investigated the efficiency of solar driven $\mathrm{Ni}$ and modified $\mathrm{N}$ doped $\mathrm{InTaO}_{4}$ using a visible light xenon lamp as light source with PE3OOBF filters [82, 108]. Pan et al. converted $\mathrm{CO}_{2}$ into methanol using $\mathrm{NiO}_{\mathrm{x}} / \mathrm{InTaO}_{4}$ as the photocatalyst. The only product of the process - methanol had a yield of $1.394 \mu \mathrm{mol} \mathrm{g}{ }^{-1} \mathrm{~h}^{-1}$ recorded [168]. $\mathrm{NiO}_{\mathrm{x}} / \mathrm{InTaO}_{4}$ was used to attract electrons and to provide active reaction sites. The relationship between the nanostructure composite and the different structures as well as their photo-activities are explained by a reaction mechanism (See Fig.. 14.). Liou et al. also reported photoreduction of $\mathrm{CO}_{2}$ to methanol using $\mathrm{NiO}$ doped $\mathrm{InTaO}_{4}$ as photocatalyst illuminated under solar spectrum of $400 \mathrm{~nm}$. The methanol yield was $0.16 \mu \mathrm{mol} \mathrm{g}^{-1} \mathrm{~h}^{-1}$ [169]. Wang et al. used $\mathrm{NiO}$ doped $\mathrm{InTaO}_{2}$ in optical fibre photoreactor with a light intensity of $327 \mathrm{mWcm}^{-2}$ and room temperature to reduce $\mathrm{CO}_{2}$ to methanol. A methanol rate of $11.1 \mu \mathrm{mol} \mathrm{g}{ }^{-1} \mathrm{~h}^{-1}$ was recorded, but when the temperature was 
increased to $75{ }^{\circ} \mathrm{C}$ the yield rate was $21.0 \mu \mathrm{mol} \mathrm{g}^{-1} \mathrm{~h}^{-1}[170]$. All these works confirm that these substitute photocatalysts performed better based on the yield of products obtained.

Several photocatalysts other than $\mathrm{TiO}_{2}$ have been used for photoreduction of $\mathrm{CO}_{2}$. The non - $\mathrm{TiO}_{2}$ catalysts can be classified into five different categories namely the metal oxides and hydroxides, metal organic frameworks (MOF) and, Oxysalts, metal chalcogenides and nitrides and polymeric materials. Table 3. Shows a list of selected non- $\mathrm{TiO}_{2}$ based materials used for photoreduction of $\mathrm{CO}_{2}$ to methanol. This table shows photocatalysts which consisted of more than one photocatalyst or heteroatom combined together in order to obtain optimum performance. Although these photocatalysts gave equal or better results compared to that obtained from using $\mathrm{TiO}_{2}$ based photocatalysts, there are also some drawbacks such as poor stability, complicated synthesis method which produce toxic by-products and difficulty or expensive in scaling up for industrial application. For example, the germanium and galliumbased materials $\left(\mathrm{ZnGa}_{2} \mathrm{O}_{4}, \mathrm{Zn}_{2} \mathrm{GeO}_{4}\right.$ etc. $)$ possess high $\mathrm{CB}$ positions and able to facilitate $\mathrm{CO}_{2}$ photoreduction. However, these materials have wide band gaps $(4.5 \mathrm{eV}$ and $4.65 \mathrm{eV})$ and less light absorption capacity than $\mathrm{TiO}_{2}[171]$.

\subsubsection{Metal oxides and hydroxides}

Metal, mixed oxides and hydroxides of different elements such as $\mathrm{Cu}$ (I) \& $\mathrm{Cu}$ (II), Ni (II), Si (II), Zn (II), Ga (III), Ge (III), Ce (IV) and layered double hydroxides have been used for photoreduction of $\mathrm{CO}_{2}$ to methanol. Copper has always been identified as a suitable dopant and co-dopant for photoreduction of $\mathrm{CO}_{2}$ to methanol since, , it is able to serve as an electron trapping agent during photoreduction of $\mathrm{CO}_{2}[172]$. When used as a dopant or codopant it also creates a Schottky barrier which helps to foster charge separation and inhibit recombination. Oxides in the $\mathrm{Cu}^{2+}$ and $\mathrm{Cu}^{+}$states have been used for photoreduction of $\mathrm{CO}_{2}$ with the $\mathrm{Cu}^{+}$state able to effectively trap visible light and function as an efficient VLR 
photocatalyst. Zinc oxide has been used for photoreduction of $\mathrm{CO}_{2}$ to, over nitrogen-doped zinc $\mathrm{CO}_{2}$ converted to methanol under an $8 \mathrm{~W}$ fluorescent tube with water vapour as the reductant. The gas phase process produced a methanol of $2 \times 10^{-4} \mu$ molg.cat. $\mathrm{h}^{-1}$ alongside $\mathrm{H}_{2}$, $\mathrm{CH}_{4}$ and $\mathrm{CO}$ as by-products [83]. Graphitic carbon nitride $\left(\mathrm{g}-\mathrm{C}_{3} \mathrm{~N}_{4}\right)$ was modified by $\mathrm{ZnO}$ nanoparticles to produce a superior photocatalyst for $\mathrm{CO}_{2}$ photoreduction. Even though there was little or no improvement to the light absorptivity of the nanocomposite, interaction between $\mathrm{ZnO}$ and $\mathrm{g}-\mathrm{C}_{3} \mathrm{~N}_{4}$ produced a photocatalyst with enhanced charge separation, high inhibition to recombination and superior performance. Methane, ethanol and carbon monoxide were also obtained and the rate of $\mathrm{CO}_{2}$ conversion was up to $45.6 \mu$ molg.cat. $h^{-1}$ [173]. Meanwhile, photoreduction of $\mathrm{CO}_{2}$ to methanol using germanium oxide, produced 1-10 $\mu \mathrm{mol} \mathrm{h}{ }^{-1} \mathrm{gcat}^{-1}$ methanol and methane using promoted $\mathrm{Zn}_{2} \mathrm{GeO}_{4}[85]$.

The oxides of cerium can be used for photocatalytic reduction of $\mathrm{CO}_{2}$ to methanol and modification with other metals or semiconductors boosts its photo-activity. Huang et al., codoped $\mathrm{Co}_{3} \mathrm{O}_{4}$ and $\mathrm{CeO}_{4}$ using a combustion method for photoreduction of $\mathrm{CO}_{2}$ to methanol and $\mathrm{C}_{2} \mathrm{H}_{5} \mathrm{OH}$ under visible light. It was obvious from the research that modification with $\mathrm{Co}_{3} \mathrm{O}_{4}$ was the sole reason for improvement in the photo-activity because neither methanol nor $\mathrm{C}_{2} \mathrm{H}_{5} \mathrm{OH}$ was detected when using pure $\mathrm{Co}_{3} \mathrm{O}_{4}$. The optimum yield of methanol and $\mathrm{C}_{2} \mathrm{H}_{5} \mathrm{OH}$ were 1.52 and $4.75 \mu$ molg.cat. $h^{-1}$ respectively [96]. Just like most $\mathrm{d}^{10}$ configuration metal oxides $\left(\mathrm{Ge}^{4+}, \mathrm{Sn}^{4+}, \mathrm{In}^{3+}\right)$ gallium oxide possess highly mobile photo-generated electrons since their $\mathrm{CB}$ contains hybridized $\mathrm{s}$ and $\mathrm{p}$ orbitals to increase photo-activity. However, only few works exist on $\mathrm{CO}_{2}$ conversion to methanol using gallium oxide or hydroxide even though it has been used to obtain other products such as $\mathrm{CH}_{4}$ [174] and $\mathrm{CO}$ [175]. Morikawa et al., reported photoreduction of $\mathrm{CO}_{2}$ to $\mathrm{CO}$ and methanol using $\mathrm{Ga}, \mathrm{Cu}$ and $\mathrm{Zn}$ modified double hydroxides under UV-visible light [176]. Jiang et al., also reported photoreduction of $\mathrm{CO}_{2}$ using ordered layered double hydroxides modified with $\mathrm{Cu}_{2} \mathrm{O}$ [177]. UV-visible light was used, 
hydrogen was the reductant and $\mathrm{CO}$ was produced alongside methanol. They reported product selectivity was dictated by the choice of metal dopant where modification with zinc produced optimum yield of $\mathrm{CO}\left(620 \mu \mathrm{molg} . \mathrm{cat}^{-1} \mathrm{~h}^{-1}\right)$ while using $\mathrm{Cu}$ gave optimal yield of methanol. Modification with $\mathrm{Cu}$ increased selectivity up to $68 \%$ and enabled photo-coupling of protons and photo-generated electrons to produce methanol

\subsubsection{Metal organic frameworks and mesoporous materials}

Metal organic frameworks (MOFs) and mesoporous materials are another class of photocatalytic materials evolving in the research of $\mathrm{CO}_{2}$ to methanol. These materials are used in almost all fields of research primarily because of large surface area, pore structure and porous nature of their morphology. Combining two catalysts or materials together often increase the surface area of the resultant photocatalyst material, but what distinguishes these set of materials is the feasibility of accurately controlling the textural properties of the material enabling high adsorption rate for $\mathrm{CO}_{2}$ for improved photo-activity, easy access of reactants to pores in the catalyst and better selectivity [178-181].

Different types of mesoporous materials have been used for photoconversion of $\mathrm{CO}_{2}$ to hydrocarbon fuels from Ti-MCM-41, TUD-1 silica matrix, $\mathrm{TiO}_{2} /$ mesoporous silica (KIT-6) [181]. Most of these mesoporous materials are hardly used alone as photocatalysts, but as cocatalysts for forming heterostructures especially with Ti. Metal organic frameworks (MOFs) have also been extensively used as photocatalysts due to their 3D crystalline structure which gives them their very large surface area, porosity and higher flexibility. Surface area and porosity are very pertinent characteristics of a viable photocatalyst for both water splitting and $\mathrm{CO}_{2}$ photoreduction therefore the MOFs have great prospects for these processes. The mesoporous materials also have organic linkers allowing migration of photo-generated electrons to metal centre easy and rapid. Unfortunately, they experience weak thermal and 
hydrothermal stability. Triethanolamine (TEA/TEOA) sacrificial reagent could improve its stability by reversal of electron deficiency [182].

For an effective $\mathrm{CO}_{2}$ photoreduction process to take place, the chosen catalyst must be soluble in water for the reaction to occur. However, this is not so for MOF as they lack connection between metal-organic linkers. The MOF can be said to be water intolerant [183186]. The intolerance of MOFs affects the photo-activity because the metal clusters will be starved of photo-generated electrons if the organic linkers are not photo-excited effectively. The choice of organic linker, metal cluster and modification for a MOF also affects the selectivity and yield of products. The use of MOFs for photoreduction of $\mathrm{CO}_{2}$ has not been fully explored. Liu et al., captured and photo-reduced $\mathrm{CO}_{2}$ to methanol using a copper modified porphyrin-based MOF. With the Cu-porphyrin based MOF, they reported a methanol production activity seven times higher than porphyrin-based MOF highlighting adsorption of $\mathrm{CO}_{2}$ onto the surface of $\mathrm{Cu}^{2+}$. The improved photo-activity is attributed to superior efficiency [187]. More research work is still needed on the application of mesoporous and MOFs for selective photoreduction of $\mathrm{CO}_{2}$ to methanol. It is expected that because of the unique properties that MOFs possess, when combined with other semiconductor materials, superior textural and morphological properties of composites or heterostructures would be produced $\mathrm{h}$. These composites or heterostructures should demonstrate better photo-activity due to the presence of MOFs.

\subsubsection{Oxysalts}

Oxysalts are another category of photocatalysts researched for photoreduction of $\mathrm{CO}_{2}$ to methanol. Common members of this group are the titanates and tantalates. Other members of this category are the tungsten-based materials, niobium based, vanadium based, and bismuth based. Though there are few or no works on using oxysalts directly, the alkaline earth titanates 
and layered titanates have been explored. Alkaline earth titanates and tantalates such as $\mathrm{SrTiO}_{3}$ [188], $\mathrm{NaTaO}_{3}$ [189], $\mathrm{KTaO}_{3}$ [190] etc. and layered titanates and perovskite tantalates like $\mathrm{Sr}_{3} \mathrm{Ti}_{2} \mathrm{O}_{7}$ [180], $\mathrm{La}_{2} \mathrm{Ti}_{2} \mathrm{O}_{7}$ [191], and $\mathrm{K}_{2} \mathrm{Ti}_{6} \mathrm{O}_{13}$ [192] have been explored. Just like the famous $\mathrm{TiO}_{2}, \mathrm{TiO}_{3}$ has also been used for photoreduction of $\mathrm{CO}_{2}$ to hydrocarbon fuels and particularly to methanol. Many of these oxysalts were used to photo-reduce $\mathrm{CO}_{2}$ to other hydrocarbon fuels such as $\mathrm{CH}_{4}$ [193], $\mathrm{H}_{2}$ [194] and also $\mathrm{CO}$ [195]. However, some have been used to obtain methanol especially after Halmann et al., converted $\mathrm{CO}_{2}$ to methanol using $\mathrm{SrTiO}_{3}$ [196]. It was noticed that because $\mathrm{SrTiO}_{3}$ had a higher $\mathrm{CB}$ than the oxidation potential of $\mathrm{CH}_{3} \mathrm{OH} / \mathrm{H}_{2} \mathrm{CO}_{3}$, photoconversion to a range of aqueous products (including methanol) was possible. Kato et al., identified that the type of metal dopant on layered pervoskites affected photo-activity and product selectivity. From their research it was confirmed the $\mathrm{Na}$ doped tantalate oxide was the most active among the alkali -metal- modified tantalate oxide used [194]. Coupling tantalate and titanate oxides with other semiconductors has also been shown to be a good way to improve photo-activity and efficiency for $\mathrm{CO}_{2}$ photoreduction.

Xiang et al., recently produced methanol from the photoreduction of $\mathrm{CO}_{2}$ using $\mathrm{CuO}$ loaded $\mathrm{NaTaO}_{3}[76]$ with isopropanol $\left(\mathrm{C}_{3} \mathrm{H}_{8} \mathrm{O}\right)$ as the reductant A high-pressure mercury lamp was used as the light source. Optimum yield of 137.48 and $335.93 \mu$ molg.cat $^{-1} \mathrm{~h}^{-1}$ was obtained for methanol and $\mathrm{C}_{3} \mathrm{H}_{6} \mathrm{O}$, respectively. Improvement in product yield was traced to the choice of dopant used, its properties and the choice of reductant. $\mathrm{C}_{3} \mathrm{H}_{8} \mathrm{O}$ functioned as an electron donor and could absorb $\mathrm{CO}_{2}$ very well. The reaction mechanism for the UV light photoreduction process is depicted in Fig. 15. The mechanism begins with the production of electron-hole pairs via photo-irradiation of the photocatalyst $\left(\mathrm{NaTaO}_{3}\right)$. Unmodified $\mathrm{NaTaO}_{3}$ has a $\mathrm{CB}$ of $-0.92 \mathrm{~V}$ vs NHE while $\mathrm{CuO}$ has a $\mathrm{CB}$ of $-0.78 \mathrm{~V}$ vs NHE [117]. Based on the principle that electrons move from a photocatalyst with higher $\mathrm{CB}$ to that of lower $\mathrm{CB}$, therefore it is evident that electrons from $\mathrm{NaTaO}_{3}$ could easily recombine with holes in $\mathrm{VB}$ of 
$\mathrm{CuO}$. This migration would further enhance electron-hole separation and hence prolong their life span [118]. Since the movement of electrons occurred in the manner described earlier it is expected that the reduction reaction (reaction of $\mathrm{CO}_{2}$ with electrons to produce methanol) would occur at the $\mathrm{CB}$ of $\mathrm{CuO}$. This was confirmed as no methanol was observed when only $\mathrm{NaTaO}_{3}$ was used as a photocatalyst [117]. The thermodynamics of the process further establishes these results because $\mathrm{NaTaO}_{3}$ has a VB of $3.13 \mathrm{~V}$ while the potential for oxidizing the reaction media (isopropanol) to acetone is $0.47 \mathrm{~V}$ [119]. This explains why a high yield of acetone instead of methanol was observed - it was easier for the reaction media to be oxidized to Acetone.

Despite the fact most titanates are often active in the UV region of the spectra, modification with metals (e.g. C, N, Fe, Ni, Co etc.) can shift their optical absorption to the visible range [197, 198]. Tungsten-based materials on the other hand are visible light responsive materials. In fact, all oxo-metalates $(\mathrm{V}, \mathrm{Mo}$ and $\mathrm{Bi})$ are. $\mathrm{WO}_{3}$ is limited by low conduction band which does not allow it to directly facilitate $\mathrm{CO}_{2}$ reduction. $\mathrm{WO}_{3}$ exhibits visible light absorption and photo-activity. The fact that it is a (visible light responsive) VLR catalyst makes it useful for $\mathrm{CO}_{2}$ photoreduction once it is modified. For example, Ohno et al., photo-reduced $\mathrm{CO}_{2}$ to methanol using $\mathrm{Au} / \mathrm{Ag}-\mathrm{g}-\mathrm{C}_{3} \mathrm{~N}_{4} / \mathrm{WO}_{3}$ under visible light via a Z-scheme. Optimum yields of 2500 and $1750 \mathrm{nmol} / \mathrm{ghr}$ were obtained for the $\mathrm{Au}$ and $\mathrm{Ag}$ modified samples, respectively. Loading the metal nanoparticles affected the photo-activity of the composites and the yield of products because it aided multi-electron photoreduction of $\mathrm{CO}_{2}$. The bare composites were 1.7 times less active compared to the metal modified ones [199]. Lais et al also reported the synthesis of pure and silver loaded $\mathrm{NaNbO}_{3}$ for photoreduction of $\mathrm{CO}_{2}$ to methanol with high selectivity owing to the multi-electron transfer facilitated by the presence of $\mathrm{Ag}$ as a cocatalyst [200]. A commonly used tungsten-based material is $\mathrm{Bi}_{2} \mathrm{WO}_{6}$ and it has also been used in photoreduction of $\mathrm{CO}_{2}$. Cheng et al. reduced $\mathrm{CO}_{2}$ to methanol 
under visible light energy and the maximum yield of methanol reported was $17 \mu$ mole $\mathrm{g}$ cat $^{-1}$ $\mathrm{h}^{-1}$ using $\mathrm{Bi}_{2} \mathrm{WO}_{6}$ hollow microsphere [97] (See Fig. 16.).

Niobium based materials have attracted some attention in photocatalysis and photoreduction of $\mathrm{CO}_{2}$. Even though limited by wide band-gap, which limits access to the UV region of the spectra, when modified $\mathrm{Nb}$ materials can perform well enough. As an example, Lee et al., synthesized $\mathrm{NiO}$ modified $\mathrm{InNbO}_{4}$ for photoreduction of $\mathrm{CO}_{2}$ to methanol using halogen lamp. A solution of $\mathrm{KHCO}_{3}$ was used as the reductant and $1 \mathrm{wt} \%$ of $\mathrm{NiO}$ gave the optimum yield of methanol - $1.4 \mu$ mole $\mathrm{g} \mathrm{cat}^{-1} \mathrm{~h}^{-1}$ [201]. The Nb-based materials might not be very exceptional for photoreduction of $\mathrm{CO}_{2}$ to methanol at the moment, but are effective for other hydrocarbon fuels e.g. $\mathrm{CH}_{4}$ [202-204]. More work can be done to improve the methanol selectivity and to enhance their performance for $\mathrm{CO}_{2}$ photoreduction generally.

Like all other oxo-metalates, vanadium-based catalysts especially $\mathrm{InVO}_{4}$ are all visible light active. It can also experience sub-band gap absorption because the depletion layer of $\mathrm{InVO}_{4}$ has vacant donor states being a transition metal-based material with $\mathrm{d}^{0}$ configuration. Comparing the band gap structure of $\mathrm{InVO}_{4}$ with other oxo-metalates $\left(\mathrm{InTaO}_{4}\right.$ and $\left.\mathrm{InNbO}_{4}\right)$, it is reasonable to say it would be almost impossible for $\left(\mathrm{InVO}_{4}\right.$ to convert $\mathrm{CO}_{2}$ to methanol. Considering Fig. 14, $\mathrm{InTaO}_{4}$ and $\mathrm{InNbO}_{4}$ are better considering their band structure and the redox potential of $\mathrm{CO}_{2} / \mathrm{CH}_{3} \mathrm{OH}$. This perspective is rather myopic because a critical look at Fig. 14 indicates that $\mathrm{InVO}_{4}$ will photo-reduce $\mathrm{CO}_{2}$ to methanol if the reaction medium used for the process is $\mathrm{KHCO}_{3}$. This is because when $\mathrm{CO}_{2}$ dissolves in $\mathrm{KHCO}_{3}$ it forms carbonate ions and considering Fig. 17. It will be possible and easier to convert to methanol with carbonate instead of gaseous $\mathrm{CO}_{2}$. The nature of the photocatalyst $\left(\mathrm{InVO}_{4}\right)$, reductant to be used $\left(\mathrm{KHCO}_{3}\right)$ and the desired product (methanol) will now dictate the choice of light to be used. Since the $\mathrm{CB}$ of $\mathrm{InVO}_{4}$ has a more negative potential than $\mathrm{CO}_{2} / \mathrm{CH}_{3} \mathrm{OH}(-0.38 \mathrm{eV})$, $\mathrm{H}_{2} \mathrm{CO}_{3} / \mathrm{CH}_{3} \mathrm{OH}(0.044 \mathrm{eV})$ and $\mathrm{CO}_{3}{ }^{2-} / \mathrm{CH}_{3} \mathrm{OH}(0.209 \mathrm{eV})$ in water, visible light will be suitable 
[205]. Choice of reductant affects the rate of feed adsorption on the photocatalyst, the performance of the photocatalyst and the efficiency of the process.

In order to improve the efficiency of the process however, modification with other metal oxides is advisable. When modified with metals or other semiconductors e.g. NiO, subband gaps are formed in its valence band due to f multiple defect sites. Lee et al., used $\mathrm{NiO}$ and $\mathrm{NiO} / \mathrm{InViO}_{4}$ for photoreduction of $\mathrm{CO}_{2}$ to methanol. Distribution of photo-generated electrons through the composite as a result of accurate $\mathrm{NiO}$ loading made the yield of products higher than e bare $\mathrm{InViO}_{4}$. The pin holes created in the $\mathrm{NiO}_{4}$ loaded $\mathrm{InViO}_{4}$ created more active sites on the composite [205]. Vanadium based materials have also been used for photoreduction of $\mathrm{CO}_{2}$ to other hydrocarbon fuels e.g. the use of $\mathrm{rGO} / \mathrm{BiVO}_{4}$ for photoreduction of $\mathrm{CO}_{2}$ to $\mathrm{CH}_{4}$ etc. Bismuth based materials are functional for visible light photoreduction of $\mathrm{CO}_{2}$. The materials are largely coupled with other semiconductors for improved photo-activity. Photoreduction of $\mathrm{CO}_{2}$ to methanol using $\mathrm{Bi}_{2} \mathrm{WO}_{6}$ hollow microspheres without co-catalyst was one of the major research reported [206]. The strategy used for the work involved anion exchange hinged on the microscale Kirkendall effect. A methanol yield of over $50 \mu$ mole $g$ cat ${ }^{-1} \mathrm{~h}^{-1}$ was obtained. The improved photo-activity and yield was attributed to more $\mathrm{CO}_{2}$ being adsorbed on the microspheres and the visible light utilization capacity of the photocatalyst [206]. Sodium bismuthate - an inorganic compound of bismuth has also been used as a photocatalyst for photoreduction of $\mathrm{CO}_{2}$ to methanol. A xenon lamp $(\lambda<400 \mathrm{~nm})$ was used as the irradiation source, a solution of water and sodium hydrogen carbonate was used as the reductant and the reaction time was $9 \mathrm{hr}$. The sodium bismuthate nanorods formed were highly photoactive and were efficient for $\mathrm{CO}_{2}$ photoreduction. Maximum yield of methanol obtained was about $0.85 \mu$ mole $\mathrm{g} \mathrm{cat}^{-1} \mathrm{~h}^{-1}$ and the photocatalyst remained active after 5 cycles [207]. Bismuth based materials remain prospective photocatalysts for $\mathrm{CO}_{2}$ photoreduction provided necessary modifications are made. 


\subsubsection{Metal chalcogenides and nitrides}

All sulphides, selenides and tellurides are known as chalcogenides. Owing to their unique properties, metal sulphides are often used as photocatalysts for $\mathrm{CO}_{2}$ photoreduction. Relatively, chalcogenides have a higher CB than many of the metal oxide semiconductors to militate unique light absorption ability. Therefore, chalcogenides are suitable for photocatalysis and photoreduction of $\mathrm{CO}_{2}$ to hydrocarbon fuels. Xiaofeng et al., reported the use of pulsed laser for photoreduction of $\mathrm{CO}_{2}$ to methanol over a $\mathrm{ZnS}$ nanoparticle catalyst. A $355 \mathrm{~nm}$ laser was used as the radiation source while $100 \mathrm{ml}$ of water as the reductant. Optimum methanol yield of about $90 \mu$ mole g cat ${ }^{-1} \mathrm{~h}^{-1}$ [208] was obtained when $100 \mathrm{mg}$ of $\mathrm{ZnS}$ was used. . In 2012, Dibenedetto et al., demonstrated conversion of $\mathrm{CO}_{2}$ to methanol by a photocatalyticenzymatic process using $\mathrm{Ru}$ modified $\mathrm{ZnS}$ as the photocatalyst. The coenzyme regeneration process was a multi-electron process involving photo-coupling of an organic radical and $\mathrm{CO}_{2} \bullet^{-}$ . ZnS has two limitations: one being low photo-stability and the other is the tendency to favour production of $\mathrm{H}_{2}$ instead of $\mathrm{CO}_{2}$ photoreduction. The former limitation can be overcome by selection of appropriate sacrificial agent e.g. (methanol [209] or $\mathrm{C}_{3} \mathrm{H}_{8} \mathrm{O}$ [210]) which would act as electron scavengers and prevent photo-corrosion [211]. Modification of $\mathrm{ZnS}$ with suitable co-dopants and or semiconductor can tune the band gap so that it becomes suitable for $\mathrm{CO}_{2}$ photoreduction instead of water splitting and $\mathrm{H}_{2}$ production [212].

Another commonly used chalcogenide is $\mathrm{Bi}_{2} \mathrm{~S}_{3}$. Having a wide absorption range in the spectra as a result of narrow band gap and the moderate ability to convert irradiated light to electrons, it is indeed a worthy photocatalyst. Pure $\mathrm{Bi}_{2} \mathrm{~S}_{3}$ is still a prospective photocatalyst because there exist only few works on $\mathrm{CO}_{2}$ photoreduction using it has not been fully explored for $\mathrm{CO}_{2}$ photoreduction due to the wide band-gap but it has been deployed for water treatment and dye photosensitization. This is why several $1 \mathrm{D}$ nanomaterials and modified forms of $\mathrm{Bi}_{2} \mathrm{~S}_{3}$ 
are been synthesized as this can adjust or tune the band gap [213]. Even though it has not been extensively used for $\mathrm{CO}_{2}$ photoreduction, Prasad et al., used $\mathrm{Bi}_{2} \mathrm{~S}_{3} / \mathrm{CdS}$ to photo-reduce $\mathrm{CO}_{2}$ to methanol under visible light. The optimum yield of methanol obtained after $6 \mathrm{hr}$ was $20 \mu$ mole $\mathrm{g}$ cat ${ }^{-1} \mathrm{~h}^{-1}$. It was noted that increase in product yield was a function of co-dopant loading though up to $45 \mathrm{wt} \%$ of CdS was loaded. There are little or no report on photoreduction of $\mathrm{CO}_{2}$ to methanol using of the chalcogenides probably because of certain limitations in their band engineering or morphology. However, many of them have been used to convert $\mathrm{CO}_{2}$ to other hydrocarbon fuels like $\mathrm{ZnTe}, \mathrm{CoTe}, \mathrm{CuS}$ and $\mathrm{Cu}_{2} \mathrm{~S}$ for $\mathrm{CH}_{4}$ [214], $\mathrm{ZnS}$ for $\mathrm{HCOOH}$ [210], $\mathrm{CdInS}_{4}$ for $\mathrm{HCOOCH}_{3}[209,213]$, and $\mathrm{ZnS}$ for $\mathrm{CO}[210,212]$. Most of the chalcogenide were not used bare but modified with different co-catalysts and semiconductors. This confirms that most of the chalcogenides are not suitable for $\mathrm{CO}_{2}$ photoreduction but given the appropriate modification method promising results could be obtained.

\subsubsection{Polymeric materials}

The latest trend in photocatalysis and $\mathrm{CO}_{2}$ photoreduction is the use of carbon-based catalysts - polymers such as graphene, graphene oxide $(\mathrm{GO})$, carbon nitride $\left(\mathrm{C}_{3} \mathrm{~N}_{4}\right)$ and conjugated polymers. These compounds are increasingly been employed for photoreduction of $\mathrm{CO}_{2}$ due to well-developed surface area, unique optical and electronic properties. Graphene as a material is a very good conductor because of its properties and this explains why in some photocatalytic and other systems it is often used as an electron donator. It is often used in place of some metals because its comparable conductivity [215]. Its oxide - GO is a unique material with similar properties like that of a semiconductor. It can and has often been used as an affordable photocatalyst especially in $\mathrm{CO}_{2}$ photoreduction. The optical properties of GO could effectively trap solar energy. It can adsorb a lot of $\mathrm{CO}_{2}$ because it has a large surface area which is highly porous. 
In terms of band gap, unlike inorganic semiconductors the band gap of GO is dictated by the C-O ratio and this can be altered during synthesis [215]. This was achieved by Hsu et al., when they synthesized GO of different oxygen content for photoreduction of $\mathrm{CO}_{2}$ using the Hummer's method. They reported the obtained GO photocatalysts had different band gap with the least having a band gap of $2.9 \mathrm{eV}$ and the widest band gap was $4.4 \mathrm{eV}$. When the three different $\mathrm{GO}$ samples were used to photo-reduce $\mathrm{CO}_{2}$, only methanol was obtained as the product and compared to the reference $\left(\mathrm{TiO}_{2} \mathrm{P} 25\right)$, the different $\mathrm{GO}$ samples gave higher product yield [216]. Shown et al., also used GO to photo-reduce $\mathrm{CO}_{2}$ to methanol under visible light. Water vapour was used as the reductant and $\mathrm{CH}_{3} \mathrm{CHO}$ was obtained as the major product while methanol was also produced. The maximum yield of methanol was $0.294 \mu$ mole cat $^{-1}$ $\mathrm{h}^{-1}$ when 10 wt. $\% \mathrm{Cu}$ was decorated on GO. The product yield was 60 times greater when $\mathrm{Cu} / \mathrm{GO}$ was used.

Another property of $\mathrm{GO}$ beneficial to $\mathrm{CO}_{2}$ photoreduction and photocatalysis in general is the fact that formation of heterostructures with other semiconductors or metals is relatively easy. This is because, the presence of several oxygenated functional groups that reside on the basal plane means that incoming noble metals or semiconductors can easily cling/attach to it and this forms a heterostructure layer at that junction. This junction can serve as an effective way to separate electron and hole pairs and this would further improve the photoactivity and reduce the rate of recombination. A good example is the photoreduction of $\mathrm{CO}_{2}$ to methanol using hexa-molybdenum cluster compounds (See Fig. 18.). In this work the authors tried to solve the problem of non-recyclable catalysts by anchoring them to photoactive supports such that they can receive support from their host and be recovered for recycle. In this case cluster-based compounds of $\mathrm{Mo}_{6}-\mathrm{Cs}_{2} \mathrm{Mo}_{6} \mathrm{Br}_{8}{ }_{8} \mathrm{Br}_{6}^{\mathrm{a}}$ and (TBA) ${ }_{2} \mathrm{Mo}_{6} \mathrm{Br}^{\mathrm{i}}{ }_{8} \mathrm{Br}^{\mathrm{a}}{ }_{6}$ were clamped on graphene oxide (GO) sheets such that by recovering GO they were also collected back. This work reported one of the highest methanol yields in literature $(1644 \mu \mathrm{mol} / \mathrm{gcat}$.$) . Each of the$ 
constituents functioned differently; $\mathrm{Mo}_{6}$ boosted the visible light absorption due to its lower band gap hence its immobilization on GO. This means after photo-excitation electrons migrated from the LUMO of $\mathrm{Mo}_{6}$ to the $\mathrm{CB}$ of $\mathrm{GO}$ where photoreduction of $\mathrm{CO}_{2}$ occurred while water splitting occurred at its VB. GO provided better charge mobility and reaction area due to its large surface area [217].

Gusain et al. also reported reduction of $\mathrm{CO}_{2}$ to methanol using $\mathrm{GO}(\mathrm{rGO})$ modified with $\mathrm{CuO}$ nanorods (See Fig. 19.). As shown below, due to the lower band gap of $\mathrm{CuO}$ and its localized surface Plasmon resonance (LSPR) from the presence of $\mathrm{Cu}$, the $1 \mathrm{D} \mathrm{CuO}$ were trapped into 2D graphene sheet. By so doing the whole heterostructure can benefit from the large surface area of rGO which provides more active sites for reaction. Reductive conversion of $\mathrm{CO}_{2}$ takes place at the $\mathrm{CB}$ of $\mathrm{CuO}$ and oxidation occurs at its $\mathrm{VB}$. When $\mathrm{CuO}$ nanorods were used for the photoreduction process, only a low yield of $175 \mu$ mole $g$ cat ${ }^{-1} \mathrm{~h}^{-1}$ was obtained because the rate of recombination was very rapid. However, the yield of methanol over $\mathrm{rGO} / \mathrm{Cu}_{2} \mathrm{O}$ and $\mathrm{rGO} / \mathrm{CuO}$ drastically improved to $862 \mu \mathrm{molg}^{-1}$ and $1228 \mu \mathrm{molg}^{-1}$ respectively. Slower recombination of electron hole pairs and better transfer of photo-generated electrons in the nanocomposite were mentioned as the reasons for improved photo-activity and increase in product yield [218]. Graphene and graphene oxide (GO) remain viable materials for photoreduction of $\mathrm{CO}_{2}$ to methanol and other hydrocarbon fuels. Another unique and prospective photocatalyst is graphitic carbon nitride $\left(g-\mathrm{C}_{3} \mathrm{~N}_{4}\right)$ based materials. Graphitic carbon nitride as a metal free photocatalyst has the following benefits; low cost, effectiveness, sustainable and less toxic, low band gap of $2.7 \mathrm{eV}$, high chemical and thermal stability, and suitable redox potential to efficiently catalyse reactions. Graphitic carbon-based materials have produced some promising results for $\mathrm{CO}_{2}$ photoreduction to methanol. It has also been employed for oxygen evolution and overall water splitting. Mao et al used $\mathrm{g}-\mathrm{C}_{3} \mathrm{~N}_{4}$ synthesized from two different precursors (urea and melamine) for $\mathrm{CO}_{2}$ photoreduction with $\mathrm{NaOH}$ as the 
reductant. From the research, the products were methanol and $\mathrm{C}_{2} \mathrm{H}_{5} \mathrm{OH}$ although the selectivity was different for the two. The main product for $\mathrm{u}-\mathrm{g}-\mathrm{C}_{3} \mathrm{~N}_{4}$ was methanol while that of $\mathrm{m}-\mathrm{g}-\mathrm{C}_{3} \mathrm{~N}_{4}$ was ethanol [219]. The yield over $\mathrm{m}-\mathrm{g}-\mathrm{C}_{3} \mathrm{~N}_{4}$ was only $8.7 \mathrm{mmol}$ for $12 \mathrm{~h}$ visible-light irradiation, while the methanol and $\mathrm{C}_{2} \mathrm{H}_{5} \mathrm{OH}$ yields over u-g- $\mathrm{C}_{3} \mathrm{~N}_{4}$ are calculated to be 15.1 mmol and $10.8 \mathrm{mmol}$, respectively. Shi et al., reported the application of Cerium oxide $\left(\mathrm{CeO}_{2}\right)$ with reduced graphene oxide/ $\mathrm{CuO}$ as a cocatalyst for photoreduction of $\mathrm{CO}_{2}$ to methanol with a high yield of $135.6 \mu \mathrm{mol} \mathrm{g} \mathrm{g}^{-1} \mathrm{cat} \mathrm{h}^{-1}$ after 5 hours of reaction. In this work they report that the presence of reduced graphene oxide $(\mathrm{rGO})$ in the composite was instrumental to the achievement of such a high product yield because it facilitated the separation of photogenerated electron and hole pairs while the selectivity of the system could be attributed to the $\mathrm{CuO}$ cocatalyst [220].

Although graphitic carbon nitride possesses exceptional properties, e it has high recombination rate of the photo-generated electron-hole pair. This draw-back is minimized by doping and other enhancement methods. $\mathrm{Pt} / \mathrm{g}-\mathrm{C}_{3} \mathrm{~N}_{4}$ has been used for $\mathrm{CO}_{2}$ photoreduction under UV-vis light and the products were methane, methanol and formaldehyde [51]. G- $\mathrm{C}_{3} \mathrm{~N}_{4}$ composites and nanomaterials have also been researched due to their large surface. For example, $\mathrm{TiO}_{2}$ was modified with $\mathrm{Cu}$ and created a nanocomposite of $\mathrm{g}-\mathrm{C}_{3} \mathrm{~N}_{4}, \mathrm{Cu}$ and $\mathrm{TiO}_{2}$ (See Fig. 20.). Tough g- $\mathrm{C}_{3} \mathrm{~N}_{4}$ has a lower band gap of $2.7 \mathrm{eV}$, when $\mathrm{Cu}$ was doped into its structure it did not perform as effective as when it was combined with $\mathrm{TiO}_{2}$. $\mathrm{Cu}$ was added as a heteroatom dopant because of its affinity for methanol during photoreduction reactions as reported form previous reports. From the results obtained, addition of $\mathrm{Cu}$ to carbon nitride reduced the band gap, recombination rate of electron and hole pairs and ultimately increased the yield of methanol from the process. The nanocomposite formed from the combination of carbon nitride, copper and titanium dioxide brought about a synergistic interaction between $\mathrm{TiO}_{2}$ and $\mathrm{g}-\mathrm{C}_{3} \mathrm{~N}_{4}$. This interaction between the two catalysts helped the composite remunerate 
the unique properties of each constituent to overcome their individual set-backs [221]. The role of the copper metal doped on $\mathrm{TiO}_{2}$ in the composite included: (1) increased active sites for $\mathrm{CO}_{2}$ adsorption, (2) increased photo-activity of $\mathrm{TiO}_{2}$ to absorb and utilize visible light and (3) development of Schottky barrier to promote separation of electron and hole pairs hence inhibiting recombination. $\mathrm{g}-\mathrm{C}_{3} \mathrm{~N}_{4}$ as a metal free visible light sensitive photocatalyst was responsible for the increased absorption of visible light by the composite [221]. This combined effect from each constituent in the composite was responsible for the optimal yield of methanol during $\mathrm{CO}_{2}$ photoreduction. Thus, $\mathrm{g}-\mathrm{C}_{3} \mathrm{~N}_{4}$ can also be considered an effective photocatalyst for photoreduction of $\mathrm{CO}_{2}$ to methanol provided appropriate co-dopant is used.

Considering the reported existing works on photoreduction of $\mathrm{CO}_{2}$ using the substitute (non- $\mathrm{TiO}_{2}$ ) photocatalysts, it is obvious that though higher product yield has been reported, some draw-backs still exist. In some cases, the materials are rare or limited in the earth crust hence they are not sustainable, are synthesized by expensive multi-step processes, synthesized at extreme temperatures, not photo-stable and/or must be modified with another compound or heteroatom which maybe toxic or produce toxic wastes. This concludes our material review and brings us to a perspective. $\mathrm{TiO}_{2}$ is a viable, stable and sustainable of all photocatalysts though other photocatalysts have also proved to be promising but they are either too expensive, toxic, complicated in synthesis or limited in application. This does not necessarily mean that $\mathrm{TiO}_{2}$ is the best or further research should not be envisioned instead the contrary is the case in that extensive and rewarding researches should be pursued. Photocatalysts with better yield and higher selectivity should be the focus as these determines the possibility of industrial application for large scale production of methanol from solar energy as this is a very promising and sustainable solution to the dilemma of continual rising energy demand and reduction of $\mathrm{CO}_{2}$ emission. 


\section{Challenges and Recommendations}

From this review, a solution to the challenges of greenhouse gases and increasing demand for energy in the world today has been discussed from a photochemical point of view. The process essentially involves the use of a suitable semiconductor which possess a narrow band gap amidst other requirements. Considering the fact, the process of $\mathrm{CO}_{2}$ photoreduction is kinetically and thermodynamically complex, the process achieved since inception can be deemed commendable even though it is not yet industrially feasible. Over the years progressive results have been obtained using different photocatalyst materials. However, there is need to do a critical assessment of the field in general and to focus in particularly on the photoreduction of $\mathrm{CO}_{2}$ to methanol as it is a versatile and useful product from $\mathrm{CO}_{2}$ photoreduction. Methanol can be used for several purposes ranging from prospects as a future fuel to be a precursor to synthesis of several important chemicals therefore it is important to do an evaluation of the progress made so far. This review has achieved this using a systematic approach, but more importantly projected and given probable solutions to the problems encountered so far.

One major problem in the field of photocatalysis and specifically $\mathrm{CO}_{2}$ photoreduction is the fact that existing materials have several limitations. Although $\mathrm{TiO}_{2}$ is widely researched, its wide band gap and poor light absorption capacity has been a draw-back over the years and though several modification methods have been employed, the desired yield and selectivity level has not been attained. Techniques such as doping, sensitization, formation of nanocomposites and heterostructures etc. have shown positive results in boosting the capabilities of $\mathrm{TiO}_{2}$. On the other hand, non- $\mathrm{TiO}_{2}$ based semiconductors with narrower band gaps have also been used for this process though many of them are expensive when compared to $\mathrm{TiO}_{2}$. Though these substitutes showed better result due to their band engineering, textural properties and characteristics, their cost, stability and toxicity (especially the toxicity of the precursors used in preparing them) remain a cause for concern. 
$\mathrm{TiO}_{2}$ is more environment friendly, stable and reusable compared to other semiconductors but is less photoactive. Due to this dilemma, there is a need for continuous search for more novel photoactive, stable and selective photocatalysts for photoreduction of $\mathrm{CO}_{2}$. These photocatalysts will have to be VLR photocatalysts that can deploy the visible range of the solar spectrum and can reduce the rate of recombination, enhance charge separation and selectively photo-reduce $\mathrm{CO}_{2}$ to specific products. The existent substitute non- $\mathrm{TiO}_{2}$ based photocatalysts have shown prospects so far e.g. g- $\mathrm{C}_{3} \mathrm{~N}_{4}$, graphene, graphene oxide etc. Therefore, improvements and modifications can be made to tune the photo-activity of these materials using the same methods used to modify $\mathrm{TiO}_{2}$. Also, the use of heterostructures (especially type II) have proven rewarding considering recent researches and efforts should be intensified in this direction. Heterostructures can effectively deploy the strong points of each constituent, improve the visible light absorption capacity and improve and increase the textural properties (surface area, pore structure etc.) of the material.

Similarly, the properties (textural, morphological and photocatalytic) of a photocatalyst are often determined by their preparative or synthesis method. The crystal facet, shape, surface area, pore structure, integration of modifiers, dopants or sensitizers etc. can be engineered during the preparation process. The calcination time, temperatures, inhibition of interfering organic materials, method of agitation etc. all determine the nature and properties of the photocatalytic material synthesized. To this end there is a need to discover/develop new, advanced methods for synthesis of photocatalysts used for $\mathrm{CO}_{2}$ photoreduction. In-depth understanding of the surface chemistry, atomic interactions and reactions taking place during the synthesis of photocatalytic materials will help to design process specific materials functional for production of desired products. The photocatalytic material used in $\mathrm{CO}_{2}$ photoreduction determines the rate of reactant $\left(\mathrm{CO}_{2}\right)$ adsorption to the surface of photocatalyst, rate of desorption of products from the bulk catalyst, the flow of electrons and holes, the rate 
of recombination and in fact the yield and selectivity. It is therefore imperative to research more into new synthesis methods or improve existing ones so that photocatalysts with better performance are obtained.

Furthermore, the knowledge of reaction mechanisms, reaction pathways, kinetic and thermodynamic analysis of the $\mathrm{CO}_{2}$ photoreduction process on a general note is still minimal. One of the uniqueness and complexities of the $\mathrm{CO}_{2}$ photoreduction process is that it is a multistep and multi electron process. Also, it is thermodynamically uphill in that, since $\mathrm{CO}_{2}$ has a very negative adiabatic electron affinity, transfer of a single electron to it is very endergonic. Also, recombination of electrons and holes take place at a rate that is two to three orders faster than that of electron transfer. Photoreduction of $\mathrm{CO}_{2}$ to methanol is specifically difficult because kinetically, it requires 6 electrons unlike $\mathrm{HCOOH}$ requiring only 2 electrons. The kinetics of $\mathrm{CO}_{2}$ photoreduction also depends on factors such as intensity of incident light and fraction absorbed etc. Considering all these, it is evident photoreduction of $\mathrm{CO}_{2}$ to methanol is a challenging task and we can say progress has been made so far. However, the only way to effectively improve the efficiency of photocatalytic materials is to have better understanding of the mechanism by which photoreaction takes place on the surface, how recombination takes place and how to tune the product selectivity. More research in the area of photochemistry and surface chemistry will produce deeper understanding of the activities at the surface of the photocatalyst and this will improve the utilization of photocatalytic materials. The use of computer simulations and advanced material characterization techniques can broaden knowledge in this aspect.

Semiconductors such as $\mathrm{TiO}_{2}$ have been extensively used for photoreduction of $\mathrm{CO}_{2}$ with commendable results. Despite the achievements recorded, most semiconductor photocatalysts still suffer from lack of chemical, thermal and photo-stability, low efficiency under certain condition and susceptibility to agglomeration. Conversely, polymeric materials 
exhibit properties such as relatively low/no toxicity, earth abundant element based and inexpensive, easy to synthesize, lightweight, flexible and easy tuneable properties [229]. Many of the polymeric photocatalysts are able to function effectively even without the presence of a noble metal e.g. g- $\mathrm{C}_{3} \mathrm{~N}_{4}$. The tunability of polymers give them certain properties such as ability to absorb light in the visible region, variable band gaps, and inherently porous. Other advantages include bi-continuous donor-acceptor architectures due to their synthetic framework, longer life time of excited charges and high charge carrier mobilities [229, 230]. Also, after photo-excitation of a photocatalyst, photo-excited $\mathrm{e}^{-}-\mathrm{h}^{+}$could separate into polaron pairs which must migrate rapidly to the surface of the photocatalyst where the actual $\mathrm{CO}_{2}$ photoreduction takes place. In the case of polymers this $\mathrm{e}^{-}-\mathrm{h}^{+}$can take place faster than in inorganic semiconductors because of the presence of stacked $\pi$ bonds present in 2D polymers such as $\mathrm{g}-\mathrm{C}_{3} \mathrm{~N}_{4}$ etc. [231]. These assembled $\pi$ bonds are able to facilitate the rapid transfer of charges from the photocatalyst to the co-catalyst or dopant. Different types of polymeric photocatalysts such as the linear, porous polymers, the covalent triazine frameworks, covalent organic frameworks and the carbon nitrides all have distinct properties that makes them suitable for application in $\mathrm{CO}_{2}$ photoreduction. Any material that has delocalized $\pi$ orbitals (double and triple bonds in organic molecules) can absorb the sunlight, creating charge carriers, which are subjected to transport the material $[231,232]$. All these classes of polymeric photocatalysts except the linear polymers have the stacked $\pi$ bonds in their framework unfortunately, research in $\pi$-conjugated polymeric materials for solar fuel generation is still in its infancy [229]. It is expected that intensifying research in the use of carbon-based polymeric materials for $\mathrm{CO}_{2}$ photoreduction could produce better result than most existing semiconductors. Although these materials have shown promising results, modification and band engineering are essential for optimal performance. 
Finally, away from the photocatalyst material design and photoreactor engineering, another major area of solar driven energy generation and conversion is the efficiency of the process and its sustainability. The thermodynamic, economic and environmental impacts of an energy generation or conversion process cannot be determined by determining the yield of products obtained (which is what most publications focus on). Considering the fact that a life cycle approach is a more accurate perspective when comparing emissions associated with any type of energy generation and conversion technology, there is a need for in-depth and detailed study of photocatalytic photoreduction reactions using advanced sustainability assessment tools such as Life Cycle Assessment (LCA) software, Exergy and preferably a combination of both software [233]. This type of approach will give a holistic and sustainability focused assessment of photocatalytic reduction of $\mathrm{CO}_{2}$ to renewable fuels and its prospects as a future approach to solving greenhouse gas emissions and energy generation.

\section{Concluding remarks}

From the discussions in this review, it has been established that photocatalysis and photoreduction of $\mathrm{CO}_{2}$ to hydrocarbon fuels provides a win-win solution to the problems of global warming and the need for alternative source of energy. A systematic record of previously used photocatalysts and recently designed ones have been discussed in this review. Likewise, the conditions which favour optimum yield and selectivity have been discussed. Challenges and limitations experienced in photoreduction of $\mathrm{CO}_{2}$ have also been discussed with useful recommendations and suggestions provided. It can be concluded from the critical review of different photocatalytic materials used for $\mathrm{CO}_{2}$ photoreduction that carbon-based materials specifically graphene based photocatalysts mostly produce the highest yield of methanol. The properties of graphene-based materials such as the surface and textural properties are responsible for this superior performance it exhibits. Since the method of preparation and 
modification affects the photo-activity of a photocatalyst, new and advanced synthesis methods should be discovered, or existing ones should be improved on. Most of the organic and polymeric compounds lose their photo-activity during preparation especially upon exposure to strong rays of light, extreme temperature and pressure. Therefore, novel polymeric materials with better photo-stability, photo-activity, band engineering and light trapping capacity should be explored.

Based on the reported yield of methanol it can be proven that polymeric and organic materials can effectively photo-reduce $\mathrm{CO}_{2}$ to methanol, but, clear details of how this process takes place is still far-fetched. Deeper understanding of the surface chemistry, atomic interactions, textural and morphological changes occurring during material synthesis is imperative. In-depth understanding of the reaction mechanisms, pathways and photo transformations during $\mathrm{CO}_{2}$ photoreduction is pivotal to development and advancement of this field of research. Of all metal atoms doped on photocatalyst materials, copper modified photocatalysts produce higher yield of methanol. The light trapping ability of copper, LSPR effect and the ease of band energy modification (especially with $\mathrm{TiO}_{2}$ ) make it preferable for photoconversion of $\mathrm{CO}_{2}$ to methanol. However, the method of modification determines how atoms of the metal will be distributed over or into the photocatalyst material. Therefore, methods or procedures with which accurate positioning and dispersion of metal dopants on a photocatalyst will help maximize the photocatalytic properties of the dopant atoms.

\section{Acknowledgements}

The authors would like to extend their deepest appreciation to the Ministry of Education (MOE, Malaysia) for the financial support given to this research under Nanomite LRGS (Long-term 
Research Grant Scheme), Vot 4L839 and Malaysia Research Star Award - Fundamental Research Grant Scheme (MRSA-FRGS), Vot 4F988.

\section{References}

[1] A. Saxena, R. Nirgun, Industrialization Has Caused Environmental Scathe, Journal of Retail Marketing \& Distribution Management 2(2) (2018) 1-5. 
[2] A. Gupta, Climate Change and Global Warming: A Critical Analysis, National Journal of Environmental Law 1(2) (2019) 37-41.

[3] N. Watts, M. Amann, S. Ayeb-Karlsson, K. Belesova, T. Bouley, M. Boykoff, P. Byass, W. Cai, D. Campbell-Lendrum, J. Chambers, The Lancet Countdown on health and climate change: from 25 years of inaction to a global transformation for public health, The Lancet 391(10120) (2018) 581-630.

[4] Y.R. du Pont, M. Meinshausen, Warming assessment of the bottom-up Paris Agreement emissions pledges, Nature communications 9(1) (2018) 4810.

[5] T.M. Letcher, Why do we have global warming?, Managing Global Warming, Elsevier2019, pp. 3-15.

[6] F.A. Rahman, M.M.A. Aziz, R. Saidur, W.A.W.A. Bakar, M. Hainin, R. Putrajaya, N.A. Hassan, Pollution to solution: Capture and sequestration of carbon dioxide (CO 2) and its utilization as a renewable energy source for a sustainable future, Renewable and Sustainable Energy Reviews 71 (2017) 112-126.

[7] I. Dincer, Renewable energy and sustainable development: a crucial review, Renewable and Sustainable Energy Reviews 4(2) (2000) 157-175.

[8] S. Shafie, T. Mahlia, H. Masjuki, A. Andriyana, Current energy usage and sustainable energy in Malaysia: a review, Renewable and Sustainable Energy Reviews 15(9) (2011) 43704377.

[9] R. York, S.E. Bell, Energy transitions or additions?: Why a transition from fossil fuels requires more than the growth of renewable energy, Energy Research \& Social Science 51 (2019) 40-43.

[10] U.E.I. Administration, Electricity explained, 2019, April 19. https://www.eia.gov/energyexplained/index.php?page=electricity_in the united_states. 
[11] Wikipedia, Renewable energy in the united states, 2019, 18 July. https://en.wikipedia.org/wiki/Renewable energy in the United States.

[12] W.d. atlas, $\mathrm{CO} 2$ emissions per capita, 2016. https://knoema.com/atlas/ranks/CO2emissions-per-capita.

[13] T.W. Bank, CO2 emissions (metric tons per capita), 2019. https://data.worldbank.org/indicator/EN.ATM.CO2E.PC?view=map.

[14] US Energy Information Administration, What is the volume of world natural gas reserves?, 2019, March 8. https://www.eia.gov/tools/faqs/faq.php?id=52\&t=8.

[15] S.-. Elseivier, Will we ever stop using fossil fuels?, 2016, January 22. http://home.uchicago.edu/ -tcovert/webfiles/jep_fossil_fuels.

[16] J. Layton, Do wind turbines cause health problems? http://science.howstuffworks.com/windturbines-health2.htm

[17] C. Oltra, R. Sala, S. Germán, S. López-Asensio, Trust perceptions among residents surrounding nuclear power plants: A descriptive and explanatory study, Progress in Nuclear Energy 113 (2019), pp. $1-6$.

[18] M.H. Balali, N. Nouri, E. Omrani, A. Nasiri, W. Otieno, An overview of the environmental, economic, and material developments of the solar and wind sources coupled with the energy storage systems, International Journal of Energy Research 41(14) (2017), pp. 1948-1962.

[19] T.A. Räsänen, O. Varis, L. Scherer, M. Kummu, Greenhouse gas emissions of hydropower in the Mekong River Basin, Environmental Research Letters 13(3) (2018), pp. 034030.

[20] O. Hanbury, V. Vasquez, Life cycle analysis of geothermal energy for power and transportation: A stochastic approach, Renewable energy 115 (2018), pp. 371-381.

[21] H. Montgomery, Preventing the progression of climate change: one drug or polypill?, Biofuel Research Journal 4(1) (2017), pp. 536-536. 
[22] R. Kiesgen de_Richter, T. Ming, S. Caillol, Fighting global warming by photocatalytic reduction of CO 2 using giant photocatalytic reactors, Renewable and Sustainable Energy Reviews 19 (2013), pp. $82-106$.

[23] C. Graves, S.D. Ebbesen, M. Mogensen, K.S. Lackner, Sustainable hydrocarbon fuels by recycling CO 2 and H 2 O with renewable or nuclear energy, Renewable and Sustainable Energy Reviews 15(1) (2011), pp. 1-23.

[24] S. Arrhenius, XXXI. On the influence of carbonic acid in the air upon the temperature of the ground, The London, Edinburgh, and Dublin Philosophical Magazine and Journal of Science 41(251) (1896), pp. 237-276.

[25] N.N. Vu, S. Kaliaguine, T.O. Do, Critical Aspects and Recent Advances in Structural Engineering of Photocatalysts for Sunlight-Driven Photocatalytic Reduction of $\mathrm{CO} 2$ into Fuels, Advanced Functional Materials (2019), p. 1901825.

[26] R. Pang, Development of Novel Photocatalysts and Co-catalysts for Photocatalytic Conversion of CO2 by H20, (2019).

https://repository.kulib.kyoto-u.ac.jp/dspace/bitstream/2433/242527/2/dkogk04606.pdf

[27] L. Spadaro, F. Arena, A. Palella, Which Future Route in the Methanol Synthesis? Photocatalytic Reduction of CO2, the New Challenge in the Solar Energy Exploitation, Methanol, Elsevier (2018), pp. $429-472$.

[28] M. Tahir, N.S. Amin, Advances in visible light responsive titanium oxide-based photocatalysts for CO2 conversion to hydrocarbon fuels, Energy Conversion and Management 76 (2013), pp. 194-214.

[29] S. Zhang, X. Yin, Y. Zheng, Enhanced photocatalytic reduction of $\mathrm{CO} 2$ to methanol by ZnO nanoparticles deposited on ZnSe nanosheet, Chemical Physics Letters 693 (2018), pp. 170-175.

[30] K. Li, B. Peng, T. Peng, Recent Advances in Heterogeneous Photocatalytic CO2 Conversion to Solar Fuels, ACS Catalysis 6(11) (2016), pp. 7485-7527.

[31] J. Mao, K. Li, T. Peng, Recent advances in the photocatalytic CO2 reduction over semiconductors, Catalysis Science \& Technology 3(10) (2013), pp. 2481. 
[32] M. Tahir, N.S. Amin, Advances in visible light responsive titanium oxide-based photocatalysts for CO 2 conversion to hydrocarbon fuels, Energy Conversion and Management 76 (2013), pp. 194-214. [33] S.-H. Liu, J.-S. Lu, Y.-C. Chen, Sustainable Recovery of CO2 by Using Visible-Light-Responsive Crystal Cuprous Oxide/Reduced Graphene Oxide, Sustainability 10(11) (2018), p. 4145.

[34] P.V. Kamat, S. Jin, Semiconductor photocatalysis:“tell us the complete story!”, ACS Publications, (2018), pp. 622-623.

[35] C. Hiragond, S. Ali, S. Sorcar, S.-I. In, Hierarchical Nanostructured Photocatalysts for CO2 Photoreduction, Catalysts 9(4) (2019), pp. 370.

[36] M. Lv, Y. Wang, L. Lu, R. Wang, S. Ni, G. Liu, X. Xu, Structural dependence of the photocatalytic properties of double perovskite compounds A $2 \mathrm{InTaO} 6(\mathrm{~A}=\mathrm{Sr}$ or $\mathrm{Ba})$ doped with nickel, Physical Chemistry Chemical Physics 18(31) (2016), pp. 21491-21499.

[37] Z. Wang, P. Liu, J. Han, C. Cheng, S. Ning, A. Hirata, T. Fujita, M. Chen, Engineering the internal surfaces of three-dimensional nanoporous catalysts by surfactant-modified dealloying, Nature communications 8(1) (2017), pp. 1066.

[38] F. Yang, D. Deng, X. Pan, Q. Fu, X. Bao, Understanding nano effects in catalysis, National Science Review 2(2) (2015), pp. 183-201.

[39] A. Víctor, D.P. Serrano, J.M. Coronado, Current Challenges of CO2 Photocatalytic Reduction Over Semiconductors Using Sunlight, From Molecules to Materials, Springer (2015), pp. 171-191.

[40] J. Zhang, B. Tian, L. Wang, M. Xing, J. Lei, Photocatalysis: Fundamentals, Materials and Applications, Springer; 2018.

[41] S. Aliwi, K. Al-Jubori, Photoreduction of $\mathrm{CO} 2$ by metal sulphide semiconductors in presence of H2S, Solar energy materials 18(3-4) (1989), pp. 223-229.

[42] I. Ganesh, Conversion of carbon dioxide into methanol-a potential liquid fuel: Fundamental challenges and opportunities (a review), Renewable and Sustainable Energy Reviews 31 (2014), pp. 221-257. 
[43] M. Goor, S. Menkin, E. Peled, High power direct methanol fuel cell for mobility and portable applications, International Journal of Hydrogen Energy 44(5) (2019), pp. 3138-3143.

[44] I. Ganesh, Conversion of Carbon Dioxide to Methanol Using Solar Energy - A Brief Review, Materials Sciences and Applications 02(10) (2011), pp. 1407-1415.

[45] K.A. Ali, A.Z. Abdullah, A.R. Mohamed, Recent development in catalytic technologies for methanol synthesis from renewable sources: A critical review, Renewable and Sustainable Energy Reviews 44 (2015), pp. 508-518.

[46] G.A. Olah, Beyond oil and gas: the methanol economy, Angew Chem Int Ed Engl 44(18) (2005), pp. 2636-2639.

[47] A. Olivo, D. Zanardo, E. Ghedini, F. Menegazzo, M. Signoretto, Solar Fuels by Heterogeneous Photocatalysis: From Understanding Chemical Bases to Process Development, ChemEngineering 2(3) (2018), p. 42.

[48] J.D. Graham, N.I. Hammer, Photocatalytic Water Splitting and Carbon Dioxide Reduction, Handbook of Climate Change Mitigation, Springer (2012), pp. 1755-1780.

[49] X. Chang, T. Wang, P. Yang, G. Zhang, J. Gong, The Development of Cocatalysts for Photoelectrochemical CO2 Reduction, Advanced Materials (2019), 31, 1804710.

[50] A. Aruchamy, G. Aravamudan, G. Subba Rao, Semiconductor based photoelectrochemical cells for solar energy conversion-An overview, Bulletin of Materials Science 4(5) (1982), pp. 483-526.

[51] J. Yu, K. Wang, W. Xiao, B. Cheng, Photocatalytic reduction of CO2 into hydrocarbon solar fuels over g-C3N4-Pt nanocomposite photocatalysts, Phys Chem Chem Phys 16(23) (2014), pp. 11492-501. [52] H.-R.M. Jhong, S. Ma, P.J.A. Kenis, Electrochemical conversion of $\mathrm{CO} 2$ to useful chemicals: current status, remaining challenges, and future opportunities, Current Opinion in Chemical Engineering 2(2) (2013), pp. 191-199.

[53] S. Xie, Q. Zhang, G. Liu, Y. Wang, Photocatalytic and photoelectrocatalytic reduction of CO 2 using heterogeneous catalysts with controlled nanostructures, Chemical communications 52(1) (2016), pp. 35-59. 
[54] M. Khalil, J. Gunlazuardi, T.A. Ivandini, A. Umar, Photocatalytic conversion of CO2 using earthabundant catalysts: A review on mechanism and catalytic performance, Renewable and Sustainable Energy Reviews 113 (2019), p. 109246.

[55] P. Zanatta, P.S.B.d. Santos, T. Mattoso, M. Lazarotto, M.L. Moreira, R. Beltrame, D.A. Gatto, Resistance of TiO2-treated Eucalyptus botryoides Wood to the Fungus Ganoderma applanatum, Floresta e Ambiente 25(3) (2018).

[56] M. Nasr, C. Eid, R. Habchi, P. Miele, M. Bechelany, Recent progress on titanium dioxide nanomaterials for photocatalytic applications, ChemSusChem 11(18) (2018), pp. 3023-3047.

[57] F. Xu, J. Zhang, B. Zhu, J. Yu, J. Xu, CuInS 2 sensitized TiO 2 hybrid nanofibers for improved photocatalytic CO 2 reduction, Applied Catalysis B: Environmental (2018), pp. 194-202.

[58] M. Li, M. Wang, L. Zhu, Y. Li, Z. Yan, Z. Shen, X. Cao, Facile microwave assisted synthesis of N-rich carbon quantum dots/dual-phase $\mathrm{TiO} 2$ heterostructured nanocomposites with high activity in CO2 photoreduction, Applied Catalysis B: Environmental 231 (2018), pp. 269-276.

[59] A. Crake, K.C. Christoforidis, A. Gregg, B. Moss, A. Kafizas, C. Petit, The Effect of Materials Architecture in TiO2/MOF Composites on $\mathrm{CO} 2$ Photoreduction and Charge Transfer, Small 15(11) (2019), 15, 1805473.

[60] S. Wang, B.Y. Guan, X.W.D. Lou, Construction of ZnIn2S4-In2O3 hierarchical tubular heterostructures for efficient CO2 photoreduction, Journal of the American Chemical Society 140(15) (2018), pp. 5037-5040.

[61] F. Xu, B. Zhu, B. Cheng, J. Yu, J. Xu, 1D/2D TiO2/MoS2 hybrid nanostructures for enhanced photocatalytic CO2 reduction, Advanced Optical Materials 6(23) (2018), p. 1800911.

[62] S. Kawamura, M.C. Puscasu, Y. Yoshida, Y. Izumi, G. Carja, Tailoring assemblies of plasmonic silver/gold and zinc-gallium layered double hydroxides for photocatalytic conversion of carbon dioxide using UV-visible light, Applied Catalysis A: General 504 (2015), pp. 238-247.

[63] L. Wang, J. Ge, A. Wang, M. Deng, X. Wang, S. Bai, R. Li, J. Jiang, Q. Zhang, Y. Luo, Designing p-Type Semiconductor-Metal Hybrid Structures for Improved Photocatalysis, Angewandte Chemie 126(20) (2014), pp. 5207-5211. 
[64] X. Wang, K. Cheng, S. Dou, Q. Chen, J. Wang, Z. Song, J. Zhang, H. Song, Enhanced photoelectrochemical performance of $\mathrm{CdO}-\mathrm{TiO} 2$ nanotubes prepared by direct impregnation, Applied Surface Science 476 (2019), pp. 136-143.

[65] D.V. Wellia, D. Fitria, S. Safni, CN-Codoped TiO2 Synthesis by Using Peroxo Sol Gel Method for Photocatalytic Reduction of Cr (VI), The Journal of Pure and Applied Chemistry Research 7(1) (2018), pp. 25-31.

[66] M. Zikriya, Y. Nadaf, P.V. Bharathy, C. Renuka, Luminescent characterization of rare earth Dy3+ ion doped $\mathrm{TiO} 2$ prepared by simple chemical co-precipitation method, Journal of Rare Earths $37(1)$ (2019), pp. 24-31.

[67] J. Li, X. Hou, T. Sun, J. Han, H. Liu, D. Li, Hydrophilic, antibacterial and photocatalytic properties of $\mathrm{TiO} 2$ composite films modified by the methods of $\mathrm{N}+$ ion implantation and doping of CNTs under visible light irradiation, Surface and Coatings Technology 365 (2019), pp. 123-128.

[68] M. Sreedhar, I.N. Reddy, C.V. Reddy, J. Shim, J. Brijitta, Highly photostable Zn-doped TiO2 thin film nanostructures for enhanced dye degradation deposited by sputtering method, Materials Science in Semiconductor Processing 85 (2018), pp. 113-121.

[69] E. Liu, L. Kang, F. Wu, T. Sun, X. Hu, Y. Yang, H. Liu, J. Fan, Photocatalytic reduction of CO2 into methanol over $\mathrm{Ag} / \mathrm{TiO} 2$ nanocomposites enhanced by surface plasmon resonance, Plasmonics 9(1) (2014), pp. 61-70.

[70] B. Tahir, M. Tahir, N.S. Amin, Gold-indium modified TiO 2 nanocatalysts for photocatalytic CO 2 reduction with H 2 as reductant in a monolith photoreactor, Applied Surface Science 338 (2015), pp. $1-14$.

[71] S. Kumar, K. Ojha, A.K. Ganguli, Interfacial Charge Transfer in Photoelectrochemical Processes, Advanced Materials Interfaces (2017), 4, p. 1600891.

[72] Q.-H. Zhang, W.-D. Han, Y.-J. Hong, J.-G. Yu, Photocatalytic reduction of CO 2 with H 2 O on Pt-loaded TiO 2 catalyst, Catalysis Today 148(3) (2009), pp. 335-340. 
[73] E. Liu, L. Qi, J. Bian, Y. Chen, X. Hu, J. Fan, H. Liu, C. Zhu, Q. Wang, A facile strategy to fabricate plasmonic $\mathrm{Cu}$ modified $\mathrm{TiO} 2$ nano-flower films for photocatalytic reduction of $\mathrm{CO} 2$ to methanol, Materials Research Bulletin 68 (2015), pp. 203-209.

[74] L. Pastrana-Martínez, A. Silva, N. Fonseca, J. Vaz, J.L. Figueiredo, J. Faria, Photocatalytic Reduction of $\mathrm{CO} 2$ with Water into Methanol and Ethanol Using Graphene Derivative-TiO2 Composites: Effect of pH and Copper (I) Oxide, Topics in Catalysis 59(15-16) (2016), pp. 1279-1291.

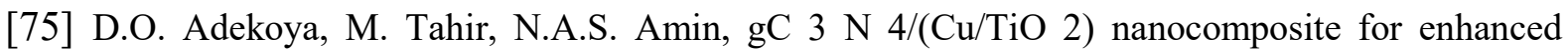
photoreduction of $\mathrm{CO} 2$ to $\mathrm{CH} 3 \mathrm{OH}$ and $\mathrm{HCOOH}$ under UV/visible light, Journal of $\mathrm{CO} 2$ Utilization 18 (2017), pp. 261-274.

[76] T. Xiang, F. Xin, J. Chen, Y. Wang, X. Yin, X. Shao, Selective photocatalytic reduction of CO2 to methanol in $\mathrm{CuO}$-loaded $\mathrm{NaTaO} 3$ nanocubes in isopropanol, Beilstein Journal of Nanotechnology 7(1) (2016), pp. 776-783.

[77] M.A. Behnajady, M. Shokri, H. Taba, N. Modirshahla, Photocatalytic activity of Cu doped TiO2 nanoparticles and comparison of two main doping procedures, Micro \&amp; Nano Letters 8(7) (2013), pp. $345-348$.

[78] M.A.M. Júnior, A. Morais, A.F. Nogueira, Boosting the solar-light-driven methanol production through $\mathrm{CO} 2$ photoreduction by loading $\mathrm{Cu} 2 \mathrm{O}$ on TiO 2-pillared $\mathrm{K} 2 \mathrm{Ti} 4 \mathrm{O}$ 9, Microporous and Mesoporous Materials 234 (2016), pp. 1-11.

[79] M. Tasbihi, K. Kočí, I. Troppová, M. Edelmannová, M. Reli, L. Čapek, R. Schomäcker, Photocatalytic reduction of carbon dioxide over $\mathrm{Cu} / \mathrm{TiO} 2$ photocatalysts, Environmental Science and Pollution Research (2017), pp. 1-9.

[80] K. Wang, J. Yu, L. Liu, L. Hou, F. Jin, Hierarchical P-doped TiO 2 nanotubes array@ Ti plate: Towards advanced CO 2 photocatalytic reduction catalysts, Ceramics International 42(14) (2016), pp. $16405-16411$.

[81] X. Zhang, F. Han, B. Shi, S. Farsinezhad, G.P. Dechaine, K. Shankar, Photocatalytic conversion of diluted $\mathrm{CO} 2$ into light hydrocarbons using periodically modulated multiwalled nanotube arrays, Angewandte Chemie International Edition 51(51) (2012), pp. 12732-12735. 
[82] C.-W. Tsai, H.M. Chen, R.-S. Liu, K. Asakura, T.-S. Chan, Ni@ NiO core-shell structuremodified nitrogen-doped InTaO4 for solar-driven highly efficient $\mathrm{CO} 2$ reduction to methanol, The Journal of Physical Chemistry C 115(20) (2011), pp. 10180-10186.

[83] P. Kumar, H.P. Mungse, O.P. Khatri, S.L. Jain, Nitrogen-doped graphene-supported copper complex: a novel photocatalyst for $\mathrm{CO} 2$ reduction under visible light irradiation, RSC Advances 5(68) (2015), pp. 54929-54935.

[84] S.A. Ansari, M.M. Khan, M.O. Ansari, M.H. Cho, Nitrogen-doped titanium dioxide (N-doped TiO 2) for visible light photocatalysis, New Journal of Chemistry 40(4) (2016), pp. 3000-3009.

[85] Y. Izumi, Recent advances in the photocatalytic conversion of carbon dioxide to fuels with water and/or hydrogen using solar energy and beyond, Coordination Chemistry Reviews 257(1) (2013), pp. $171-186$.

[86] Y.N. Kavil, Y.A. Shaban, R.K. Al Farawati, M.I. Orif, M. Zobidi, S.U. Khan, Photocatalytic conversion of $\mathrm{CO} 2$ into methanol over $\mathrm{Cu}-\mathrm{C} / \mathrm{TiO} 2$ nanoparticles under $\mathrm{UV}$ light and natural sunlight, Journal of Photochemistry and Photobiology A: Chemistry 347 (2017), pp. 244-253.

[87] G. Liao, S. Chen, X. Quan, H. Yu, H. Zhao, Graphene oxide modified gC 3 N 4 hybrid with enhanced photocatalytic capability under visible light irradiation, Journal of Materials Chemistry 22(6) (2012), pp. 2721-2726.

[88] Y. Wang, Q. Wang, X. Zhan, F. Wang, M. Safdar, J. He, Visible light driven type II heterostructures and their enhanced photocatalysis properties: a review, Nanoscale 5(18) (2013), pp. 8326-8339.

[89] R.S. Selinsky, Q. Ding, M.S. Faber, J.C. Wright, S. Jin, Quantum dot nanoscale heterostructures for solar energy conversion, Chemical Society Reviews 42(7) (2013), pp. 2963-2985.

[90] G. Lofrano, L. Rizzo, M. Grassi, V. Belgiorno, Advanced oxidation of catechol: A comparison among photocatalysis, Fenton and photo-Fenton processes, Desalination 249(2) (2009), pp. 878-883. [91] T. Inoue, A. Fujishima, S. Konishi, K. Honda, Photoelectrocatalytic reduction of carbon dioxide in aqueous suspensions of semiconductor powders, Nature 277 (1979), pp. 637-638. 
[92] M.A. Lazar, S. Varghese, S.S. Nair, Photocatalytic water treatment by titanium dioxide: recent updates, Catalysts 2(4) (2012), pp. 572-601.

[93] H.W. Nasution, E. Purnama, S. Kosela, J. Gunlazuardi, Photocatalytic reduction of CO 2 on copper-doped titania catalysts prepared by improved-impregnation method, Catalysis Communications 6(5) (2005), pp. 313-319.

[94] S. Zeng, P. Kar, U.K. Thakur, K. Shankar, A review on photocatalytic CO2 reduction using perovskite oxide nanomaterials, Nanotechnology 29(5) (2018), p. 052001.

[95] D. Maznichenko, 3-D Fibrous Network of TiO2 Nanoparticles: Raman Sensor Development, (2012).

[96] Y. Huang, C.-F. Yan, C.-Q. Guo, S.-L. Huang, Enhanced Photoreduction Activity of Carbon Dioxide over $\mathrm{Co} 3 \mathrm{O} 4 / \mathrm{CeO} 2$ Catalysts under Visible Light Irradiation, International Journal of Photoenergy (2015).

[97] H. Cheng, B. Huang, Y. Liu, Z. Wang, X. Qin, X. Zhang, Y. Dai, An anion exchange approach to Bi 2 WO 6 hollow microspheres with efficient visible light photocatalytic reduction of CO 2 to methanol, Chemical Communications 48(78) (2012), pp. 9729-9731.

[98] W. Dai, J. Yu, H. Xu, X. Hu, X. Luo, L. Yang, X. Tu, Synthesis of hierarchical flower-like Bi 2 MoO 6 microspheres as efficient photocatalyst for photoreduction of $\mathrm{CO} 2$ into solar fuels under visible light, CrystEngComm 18(19) (2016), pp. 3472-3480.

[99] N. Zhang, S. Liu, Y.-J. Xu, Recent progress on metal core@ semiconductor shell nanocomposites as a promising type of photocatalyst, Nanoscale 4(7) (2012), pp. 2227-2238.

[100] A. Lais, M. Gondal, M. Dastageer, F. Al-Adel, Experimental parameters affecting the photocatalytic reduction performance of $\mathrm{CO} 2$ to methanol: A review, International Journal of Energy Research 42(6) (2018), pp. 2031-2049.

[101] A. Kumar, P. Kumar, S.L. Jain, Nanostructured Composite Materials for CO2 Activation, Advances in Nanostructured Composites: Volume 1: Carbon Nanotube and Graphene Composites (2019), p. 174. 
[102] H. Rao, C.-H. Lim, J. Bonin, G.M. Miyake, M. Robert, Visible-Light-Driven Conversion of CO2 to CH4 with an Organic Sensitizer and an Iron Porphyrin Catalyst, Journal of the American Chemical Society 140(51) (2018), pp. 17830-17834.

[103] D. Uner, M.M. Oymak, B. İpek, CO 2 utilisation by photocatalytic conversion to methane and methanol, International Journal of global warming 3(1-2) (2011), pp. 142-162.

[104] J.M. Meichtry, H.B. Rodríguez, Sensitization of TiO2 by Dyes: A Way to Extend the Range of Photocatalytic Activity of $\mathrm{TiO} 2$ to the Visible Region, Visible-Light-Active Photocatalysis: Nanostructured Catalyst Design, Mechanisms, and Applications (2018).

[105] R. Nie, W. Ma, Y. Dong, Y. Xu, J. Wang, J. Wang, H. Jing, Artificial Photosynthesis of Methanol by Mn: CdS and CdSeTe Quantum Dot Cosensitized Titania Photocathode in Imine-Based Ionic Liquid Aqueous Solution, ChemCatChem 10(15) (2018), pp. 3342-3350.

[106] H. Lu, G.M. Carroll, N.R. Neale, M.C. Beard, Infrared Quantum Dots: Progress, Challenges, and Opportunities, ACS nano 13(2) (2019), pp. 939-953.

[107] E.H. Sargent, Colloidal quantum dot solar cells, Nature photonics 6(3) (2012), pp. 133-135.

[108] R. Marschall, Semiconductor composites: strategies for enhancing charge carrier separation to improve photocatalytic activity, Advanced Functional Materials 24(17) (2014), pp. 2421-2440.

[109] Y.-R. Lv, R. Huo, S.-Y. Yang, Y.-Q. Liu, X.-J. Li, Y.-H. Xu, Self-assembled synthesis of PbS quantum dots supported on polydopamine encapsulated BiVO4 for enhanced visible-light-driven photocatalysis, Separation and Purification Technology 197 (2018), pp. 281-288.

[110] G. Rajender, J. Kumar, P. Giri, Interfacial charge transfer in oxygen deficient TiO2-graphene quantum dot hybrid and its influence on the enhanced visible light photocatalysis, Applied Catalysis B: Environmental 224 (2018), pp. 960-972.

[111] H.L. Wu, X.B. Li, C.H. Tung, L.Z. Wu, Semiconductor Quantum Dots: An Emerging Candidate for CO2 Photoreduction, Advanced Materials (2019), 31, p. 1900709.

[112] S. Roy, E. Reisner, Visible-light driven $\mathrm{CO} 2$ reduction by mesoporous carbon nitride modified with polymeric cobalt phthalocyanine, Angewandte Chemie (2019), 131, p. 12308. 
[113] K. Kočí, L. Obalová, L. Matějová, D. Plachá, Z. Lacný, J. Jirkovský, O. Šolcová, Effect of TiO2 particle size on the photocatalytic reduction of CO2, Applied Catalysis B: Environmental 89(3-4) (2009), pp. 494-502.

[114] J. Wang, G. Ji, Y. Liu, M. Gondal, X. Chang, Cu 2 O/TiO 2 heterostructure nanotube arrays prepared by an electrodeposition method exhibiting enhanced photocatalytic activity for $\mathrm{CO} 2$ reduction to methanol, Catalysis Communications 46 (2014), pp. 17-21.

[115] C. Tang, W. Hou, E. Liu, X. Hu, J. Fan, CeF 3/TiO 2 composite as a novel visible-light-driven photocatalyst based on upconversion emission and its application for photocatalytic reduction of $\mathrm{CO} 2$, Journal of Luminescence 154 (2014), pp. 305-309.

[116] M. Ge, C. Cao, J. Huang, S. Li, Z. Chen, K.-Q. Zhang, S. Al-Deyab, Y. Lai, A review of onedimensional TiO 2 nanostructured materials for environmental and energy applications, Journal of Materials Chemistry A 4(18) (2016), pp. 6772-6801.

[117] W.-J. Ong, L.-L. Tan, S.-P. Chai, S.-T. Yong, A.R. Mohamed, Surface charge modification via protonation of graphitic carbon nitride $(\mathrm{gC} 3 \mathrm{~N} 4$ ) for electrostatic self-assembly construction of 2D/2D reduced graphene oxide $(\mathrm{rGO}) / \mathrm{gC} 3 \mathrm{~N} 4$ nanostructures toward enhanced photocatalytic reduction of carbon dioxide to methane, Nano Energy 13 (2015), pp. 757-770.

[118] J. Benedetti, D. Bernardo, A. Morais, J. Bettini, A. Nogueira, Synthesis and characterization of a quaternary nanocomposite based on $\mathrm{TiO} 2 / \mathrm{CdS} / \mathrm{rGO} / \mathrm{Pt}$ and its application in the photoreduction of CO 2 to methane under visible light, RSC Advances 5(43) (2015), pp. 33914-33922.

[119] T.L. Thompson, J.T. Yates, TiO 2-based photocatalysis: surface defects, oxygen and charge transfer, Topics in Catalysis 35(3-4) (2005), pp. 197-210.

[120] G. Ou, Y. Xu, B. Wen, R. Lin, B. Ge, Y. Tang, Y. Liang, C. Yang, K. Huang, D. Zu, Tuning defects in oxides at room temperature by lithium reduction, Nature communications 9(1) (2018), p. 1302.

[121] S. Chen, Y. Xiao, Y. Wang, Z. Hu, H. Zhao, W. Xie, A facile approach to prepare black TiO2 with oxygen vacancy for enhancing photocatalytic activity, Nanomaterials 8(4) (2018), p. 245. 
[122] M. Kong, Y. Li, X. Chen, T. Tian, P. Fang, F. Zheng, X. Zhao, Tuning the relative concentration ratio of bulk defects to surface defects in $\mathrm{TiO} 2$ nanocrystals leads to high photocatalytic efficiency, Journal of the American Chemical Society 133(41) (2011), pp. 16414-16417.

[123] H. Liu, H. Ma, X. Li, W. Li, M. Wu, X. Bao, The enhancement of TiO2 photocatalytic activity by hydrogen thermal treatment, Chemosphere 50(1) (2003), pp. 39-46.

[124] J. Carneiro, S. Azevedo, F. Fernandes, E. Freitas, M. Pereira, C. Tavares, S. Lanceros-Méndez, V. Teixeira, Synthesis of iron-doped TiO 2 nanoparticles by ball-milling process: the influence of process parameters on the structural, optical, magnetic, and photocatalytic properties, Journal of Materials Science 49(21) (2014), pp. 7476-7488.

[125] L. Kong, C. Wang, H. Zheng, X. Zhang, Y. Liu, Defect-induced yellow color in Nb-doped TiO2 and its impact on visible-light photocatalysis, The Journal of Physical Chemistry C 119(29) (2015), pp. 16623-16632.

[126] N. Feng, F. Liu, M. Huang, A. Zheng, Q. Wang, T. Chen, G. Cao, J. Xu, J. Fan, F. Deng, Unravelling the efficient photocatalytic activity of boron-induced Ti $3+$ species in the surface layer of TiO 2, Scientific reports 6 (2016), pp. 34765.

[127] Y. Yan, M. Han, A. Konkin, T. Koppe, D. Wang, T. Andreu, G. Chen, U. Vetter, J.R. Morante, P. Schaaf, Slightly hydrogenated TiO 2 with enhanced photocatalytic performance, Journal of Materials Chemistry A 2(32) (2014), pp. 12708-12716.

[128] H. He, D. Huang, W. Pang, D. Sun, Q. Wang, Y. Tang, X. Ji, Z. Guo, H. Wang, Plasma-induced amorphous shell and deep cation-site $\mathrm{S}$ doping endow $\mathrm{TiO} 2$ with extraordinary sodium storage performance, Advanced Materials 30(26) (2018), 30, p. 1801013.

[129] D. Ariyanti, L. Mills, J. Dong, Y. Yao, W. Gao, NaBH4 modified TiO2: Defect site enhancement related to its photocatalytic activity, Materials Chemistry and Physics 199 (2017), pp. 571-576.

[130] J. Dong, J. Han, Y. Liu, A. Nakajima, S. Matsushita, S. Wei, W. Gao, Defective black TiO2 synthesized via anodization for visible-light photocatalysis, ACS applied materials \& interfaces 6(3) (2014), pp. 1385-1388. 
[131] S.G. Ullattil, P. Periyat, A 'one pot'gel combustion strategy towards Ti3+ self-doped 'black'anatase TiO2- x solar photocatalyst, Journal of Materials Chemistry A 4(16) (2016), pp. 58545858.

[132] J.-Y. Liu, X.-Q. Gong, A.N. Alexandrova, Mechanism of CO2 Photocatalytic Reduction to Methane and Methanol on Defected Anatase TiO2 (101): A Density Functional Theory Study, The Journal of Physical Chemistry C 123(6) (2019), pp. 3505-3511.

[133] S. Allakhverdiev, S. Ramakrishna, A random walk to and through the photoelectrochemical cells based on photosynthetic systems, Biofuel Research Journal 2(2) (2015), pp. 222-222.

[134] D. Sudha, P. Sivakumar, Review on the photocatalytic activity of various composite catalysts, Chemical Engineering and Processing: Process Intensification 97 (2015), pp. 112-133.

[135] G. Sharma, D. Kumar, A. Kumar, H. Ala'a, D. Pathania, M. Naushad, G.T. Mola, Revolution from monometallic to trimetallic nanoparticle composites, various synthesis methods and their applications: A review, Materials Science and Engineering: C (2016), 71, pp. 1216-1230.

[136] Z. Thammavongsy, T. Seda, L.N. Zakharov, W. Kaminsky, J.D. Gilbertson, Ligand-based reduction of CO2 and release of CO on iron (II), Inorg. Chem 51(17) (2012), pp. 9168-9170.

[137] Y. Lee, S. Kim, J.K. Kang, S.M. Cohen, Photocatalytic CO 2 reduction by a mixed metal (Zr/Ti), mixed ligand metal-organic framework under visible light irradiation, Chemical Communications 51(26) (2015), pp. 5735-5738.

[138] R.A. Voloshin, V.D. Kreslavski, S.K. Zharmukhamedov, V.S. Bedbenov, S. Ramakrishna, S.I. Allakhverdiev, Photoelectrochemical cells based on photosynthetic systems: a review, Biofuel Research Journal 2(2) (2015), pp. 227-235.

[139] R. Khnayzer, V. Thoi, M. Nippe, A. King, J. Jurss, K. El Roz, J. Long, C. Chang, F. Castellano, Towards a comprehensive understanding of visible-light photogeneration of hydrogen from water using cobalt (II) polypyridyl catalysts, Energy \& Environmental Science 7(4) (2014), pp. 1477-1488.

[140] D. Hong, Y. Tsukakoshi, H. Kotani, T. Ishizuka, T. Kojima, Visible-Light-Driven Photocatalytic CO2 Reduction by a Ni (II) Complex Bearing a Bioinspired Tetradentate Ligand for Selective CO Production, Journal of the American Chemical Society 139(19) (2017), pp. 6538-6541. 
[141] C. Matlachowski, B. Braun, S. Tschierlei, M. Schwalbe, Photochemical CO2 Reduction Catalyzed by Phenanthroline Extended Tetramesityl Porphyrin Complexes Linked with a Rhenium (I) Tricarbonyl Unit, Inorganic chemistry 54(21) (2015), pp. 10351-10360.

[142] D.J. Boston, Y.M.F. Pachón, R.O. Lezna, N. De Tacconi, F.M. MacDonnell, Electrocatalytic and photocatalytic conversion of $\mathrm{CO} 2$ to methanol using ruthenium complexes with internal pyridyl cocatalysts, Inorganic chemistry 53(13) (2014), pp. 6544-6553.

[143] H. Fei, M.D. Sampson, Y. Lee, C.P. Kubiak, S.M. Cohen, Photocatalytic CO2 reduction to formate using a Mn (I) molecular catalyst in a robust metal-organic framework, Inorganic chemistry 54(14) (2015), pp. 6821-6828.

[144] R. Reithmeier, C. Bruckmeier, B. Rieger, Conversion of $\mathrm{CO} 2$ via visible light promoted homogeneous redox catalysis, Catalysts 2(4) (2012), pp. 544-571.

[145] D.J. Boston, C. Xu, D.W. Armstrong, F.M. MacDonnell, Photochemical reduction of carbon dioxide to methanol and formate in a homogeneous system with pyridinium catalysts, Journal of the American Chemical Society 135(44) (2013), pp. 16252-16255.

[146] P. Kumar, B. Sain, S.L. Jain, Photocatalytic reduction of carbon dioxide to methanol using a ruthenium trinuclear polyazine complex immobilized on graphene oxide under visible light irradiation, Journal of Materials Chemistry A 2(29) (2014), pp. 11246-11253.

[147] M. Daud, A. Rahman, Photo-Catalytic Reduction of Carbon Dioxide Over Alumina Doped Titanium Dioxide Catalyst, (2013).

[148] T. Yui, A. Kan, C. Saitoh, K. Koike, T. Ibusuki, O. Ishitani, Photochemical reduction of CO2 using TiO2: effects of organic adsorbates on $\mathrm{TiO} 2$ and deposition of $\mathrm{Pd}$ onto TiO2, ACS applied materials \& interfaces 3(7) (2011), pp. 2594-2600.

[149] Y. Lee, S. Kim, H. Fei, J.K. Kang, S.M. Cohen, Photocatalytic CO 2 reduction using visible light by metal-monocatecholato species in a metal-organic framework, Chemical Communications 51(92) (2015), pp. 16549-16552. 
[150] Y. Wang, F. Xin, J. Chen, T. Xiang, X. Yin, Photocatalytic reduction of CO2 in isopropanol on $\mathrm{Bi} 2 \mathrm{~S} 3$ quantum dots/TiO2 nanosheets with exposed $\{001\}$ facets, Journal of Nanoscience and Nanotechnology 17(3) (2017), pp. 1863-1869.

[151] S. Krejčíková, L. Matějová, K. Kočí, L. Obalová, Z. Matěj, L. Čapek, O. Šolcová, Preparation and characterization of Ag-doped crystalline titania for photocatalysis applications, Applied Catalysis B: Environmental 111 (2012), pp. 119-125.

[152] A. Sharma, B.-K. Lee, Photocatalytic reduction of carbon dioxide to methanol using nickel-loaded TiO2 supported on activated carbon fiber, Catalysis Today 298 (2017), pp. 158167.

[153] X. Li, H. Liu, D. Luo, J. Li, Y. Huang, H. Li, Y. Fang, Y. Xu, L. Zhu, Adsorption of $\mathrm{CO} 2$ on heterostructure $\mathrm{CdS}(\mathrm{Bi} 2 \mathrm{~S} 3) / \mathrm{TiO} 2$ nanotube photocatalysts and their photocatalytic activities in the reduction of $\mathrm{CO} 2$ to methanol under visible light irradiation, Chemical Engineering Journal 180 (2012), pp. 151-158.

[154] C. Wang, R.L. Thompson, J. Baltrus, C. Matranga, Visible light photoreduction of CO2 using $\mathrm{CdSe} / \mathrm{Pt} / \mathrm{TiO} 2$ heterostructured catalysts, The Journal of Physical Chemistry Letters 1(1) (2009), pp. 48-53.

[155] Q. Wang, W. Wu, J. Chen, G. Chu, K. Ma, H. Zou, Novel synthesis of ZnPc/TiO2 composite particles and carbon dioxide photo-catalytic reduction efficiency study under simulated solar radiation conditions, Colloids and Surfaces A: Physicochemical and Engineering Aspects 409 (2012), pp. 118-125.

[156] K. Thamaraiselvi, T. Sivakumar, Photocatalytic reduction of carbon dioxide by using Bare and copper oxide impregnated nano titania catalysts, Journal of nanoscience and nanotechnology 17(1) (2017), pp. 313-322.

[157] A. Hospodková, O. Šolcová, Effect of silver doping on the TiO2 for photocatalytic reduction of CO2, Applied Catalysis B: Environmental 96 (2010), pp. 239-244. 
[158] W. Tu, Y. Li, L. Kuai, Y. Zhou, Q. Xu, H. Li, X. Wang, M. Xiao, Z. Zou, Construction of unique two-dimensional MoS 2-TiO 2 hybrid nanojunctions: MoS 2 as a promising costeffective cocatalyst toward improved photocatalytic reduction of CO 2 to methanol, Nanoscale 9(26) (2017), pp. 9065-9070.

[159] S. Liu, J. Xia, J. Yu, Amine-functionalized titanate nanosheet-assembled yolk@ shell microspheres for efficient cocatalyst-free visible-light photocatalytic $\mathrm{CO} 2$ reduction, ACS applied materials \& interfaces 7(15) (2015), pp. 8166-8175.

[160] X. Cheng, R. Chen, X. Zhu, Q. Liao, L. An, D. Ye, X. He, S. Li, L. Li, An optofluidic planar microreactor for photocatalytic reduction of $\mathrm{CO} 2$ in alkaline environment, Energy 120 (2017), pp. 276-282.

[161] Q.D. Truong, H.T. Hoa, D.-V.N. Vo, T.S. Le, Controlling the shape of anatase nanocrystals for enhanced photocatalytic reduction of CO 2 to methanol, New Journal of Chemistry 41(13) (2017), pp. 5660-5668.

[162] Z. He, L. Wen, D. Wang, Y. Xue, Q. Lu, C. Wu, J. Chen, S. Song, Photocatalytic reduction of $\mathrm{CO} 2$ in aqueous solution on surface-fluorinated anatase $\mathrm{TiO} 2$ nanosheets with exposed $\{001\}$ facets, Energy \& Fuels 28(6) (2014), pp. 3982-3993.

[163] X. Li, Q. Wang, Y. Zhao, W. Wu, J. Chen, H. Meng, Green synthesis and photo-catalytic performances for ZnO-reduced graphene oxide nanocomposites, Journal of colloid and interface science 411 (2013), pp. 69-75.

[164] Q. Zhang, C.-F. Lin, Y.H. Jing, C.-T. Chang, Photocatalytic reduction of carbon dioxide to methanol and formic acid by graphene-TiO2, Journal of the Air \& Waste Management Association 64(5) (2014), pp. 578-585.

[165] J. Liu, Y. Niu, X. He, J. Qi, X. Li, Photocatalytic reduction of CO 2 using TiO 2-graphene nanocomposites, Journal of Nanomaterials 1 (2016), p. 6012896. 
[166] H. Li, S. Gan, H. Wang, D. Han, L. Niu, Intercorrelated Superhybrid of AgBr Supported on Graphitic-C3N4-Decorated Nitrogen-Doped Graphene: High Engineering Photocatalytic Activities for Water Purification and CO2 Reduction, Advanced Materials 27(43) (2015), pp. 6906-6913.

[167] R. Li, W. Zhang, K. Zhou, Metal-Organic-Framework-Based Catalysts for Photoreduction of CO2, Advanced Materials 30(35) (2018), pp. 1705512.

[168] P.-W. Pan, Y.-W. Chen, Photocatalytic reduction of carbon dioxide on NiO/InTaO 4 under visible light irradiation, Catalysis Communications 8(10) (2007), pp. 1546-1549.

[169] P.-Y. Liou, S.-C. Chen, J.C. Wu, D. Liu, S. Mackintosh, M. Maroto-Valer, R. Linforth, Photocatalytic $\mathrm{CO} 2$ reduction using an internally illuminated monolith photoreactor, Energy \& Environmental Science 4(4) (2011), pp. 1487-1494.

[170] Z.-Y. Wang, H.-C. Chou, J.C. Wu, D.P. Tsai, G. Mul, CO 2 photoreduction using NiO/InTaO 4 in optical-fiber reactor for renewable energy, Applied Catalysis A: General 380(1) (2010), pp. 172-177. [171] Q. Liu, Y. Zhou, Z. Tian, X. Chen, J. Gao, Z. Zou, Zn 2 GeO 4 crystal splitting toward sheaflike, hyperbranched nanostructures and photocatalytic reduction of $\mathrm{CO} 2$ into $\mathrm{CH} 4$ under visible light after nitridation, Journal of Materials Chemistry 22(5) (2012), pp. 2033-2038.

[172] H.W.N. Slamet, E. Purnama, K. Riyani, J. Gunlazuardi, Effect of copper species in a photocatalytic synthesis of methanol from carbon dioxide over copper-doped titania catalysts, World Appl Sci J 6(1) (2009), pp. 112-122.

[173] Y. He, Y. Wang, L. Zhang, B. Teng, M. Fan, High-efficiency conversion of CO2 to fuel over ZnO/g-C3N4 photocatalyst, Applied Catalysis B: Environmental 168-169 (2015), pp. 1-8.

[174] H.-a. Park, J.H. Choi, K.M. Choi, D.K. Lee, J.K. Kang, Highly porous gallium oxide with a high $\mathrm{CO} 2$ affinity for the photocatalytic conversion of carbon dioxide into methane, Journal of Materials Chemistry 22(12) (2012), pp. 5304-5307. 
[175] K. Teramura, H. Tsuneoka, T. Shishido, T. Tanaka, Effect of H 2 gas as a reductant on photoreduction of CO 2 over a Ga 2 O 3 photocatalyst, Chemical Physics Letters 467(1) (2008), pp. 191-194.

[176] M. Morikawa, N. Ahmed, Y. Yoshida, Y. Izumi, Photoconversion of carbon dioxide in zinccopper-gallium layered double hydroxides: the kinetics to hydrogen carbonate and further to CO/methanol, Applied Catalysis B: Environmental 144 (2014), pp. 561-569.

[177] H. Jiang, K.-i. Katsumata, J. Hong, A. Yamaguchi, K. Nakata, C. Terashima, N. Matsushita, M. Miyauchi, A. Fujishima, Photocatalytic reduction of $\mathrm{CO} 2$ on $\mathrm{Cu} 2 \mathrm{O}-$ loaded $\mathrm{Zn}-\mathrm{Cr}$ layered double hydroxides, Applied Catalysis B: Environmental 224 (2018), pp. 783-790.

[178] T.-C. Yang, F.-C. Chang, C.-Y. Peng, H.P. Wang, Y.-L. Wei, Photocatalytic reduction of CO2 with $\mathrm{SiC}$ recovered from silicon sludge wastes, Environmental technology 36(23) (2015), pp. 29872990.

[179] M.S. Hamdy, R. Amrollahi, I. Sinev, B. Mei, G. Mul, Strategies to design efficient silicasupported photocatalysts for reduction of CO2, Journal of the American Chemical Society 136(2) (2013), pp. 594-597.

[180] S.W. Jo, B.S. Kwak, K.M. Kim, J.Y. Do, N.-K. Park, S.O. Ryu, H.-J. Ryu, J.-I. Baek, M. Kang, Effectively $\mathrm{CO} 2$ photoreduction to $\mathrm{CH} 4$ by the synergistic effects of $\mathrm{Ca}$ and $\mathrm{Ti}$ on Ca-loaded TiSiMCM-41 mesoporous photocatalytic systems, Applied Surface Science 355 (2015), pp. 891-901.

[181] M. Hussain, P. Akhter, N. Russo, G. Saracco, New optimized mesoporous silica incorporated isolated Ti materials towards improved photocatalytic reduction of carbon dioxide to renewable fuels, Chemical Engineering Journal 278 (2015), pp. 279-292.

[182] M. Marszewski, S. Cao, J. Yu, M. Jaroniec, Semiconductor-based photocatalytic CO2conversion, Mater. Horiz. 2(3) (2015), pp. 261-278.

[183] D. Sun, Y. Fu, W. Liu, L. Ye, D. Wang, L. Yang, X. Fu, Z. Li, Studies on Photocatalytic CO2 Reduction over NH2-Uio-66 (Zr) and Its Derivatives: Towards a Better Understanding of Photocatalysis on Metal-Organic Frameworks, Chemistry-A European Journal 19(42) (2013), pp. $14279-14285$. 
[184] Z. Zhang, J. Li, X. Wang, Y. Huang, M. Zengb, J. Xub, Materials Chemistry A, Synthesis 120 110.43 .

[185] H.-Q. Xu, J. Hu, D. Wang, Z. Li, Q. Zhang, Y. Luo, S.-H. Yu, H.-L. Jiang, Visible-Light Photoreduction of $\mathrm{CO} 2$ in a Metal-Organic Framework: Boosting Electron-Hole Separation via Electron Trap States, Journal of the American Chemical Society 137(42) (2015), pp. 13440-13443.

[186] D. Sun, W. Liu, Y. Fu, Z. Fang, F. Sun, X. Fu, Y. Zhang, Z. Li, Noble Metals Can Have Different Effects on Photocatalysis Over Metal-Organic Frameworks (MOFs): A Case Study on M/NH2-MIL$125(\mathrm{Ti})(\mathrm{M}=\mathrm{Pt}$ and Au), Chemistry-A European Journal 20(16) (2014), pp. 4780-4788.

[187] Y. Liu, Y. Yang, Q. Sun, Z. Wang, B. Huang, Y. Dai, X. Qin, X. Zhang, Chemical Adsorption Enhanced CO2 Capture and Photoreduction over a Copper Porphyrin Based Metal Organic Framework, ACS applied materials \& interfaces 5(15) (2013), pp. 7654-7658.

[188] M. Ulman, A. Tinnemans, A. Mackor, B. Aurian-Blajeni, M. Halmann, Photoreduction of carbon dioxide to formic acid, formaldehyde, methanol, acetaldehyde and ethanol using aqueous suspensions of strontium titanate with transition metal additives, International journal of solar energy 1(3) (1982), pp. 213-222.

[189] Z. Huang, S. Yoshizawa, K. Teramura, H. Asakura, S. Hosokawa, T. Tanaka, Photocatalytic Conversion of Carbon Dioxide over A2BTa5O15 $(\mathrm{A}=\mathrm{Sr}, \mathrm{Ba} ; \mathrm{B}=\mathrm{K}, \mathrm{Na})$ Using Ammonia as an Efficient Sacrificial Reagent, ACS Sustainable Chemistry \& Engineering 6(7) (2018), pp. 8247-8255. [190] X. Shao, X. Yin, J. Wang, Nanoheterostructures of potassium tantalate and nickel oxide for photocatalytic reduction of carbon dioxide to methanol in isopropanol, Journal of colloid and interface science 512 (2018), pp. 466-473.

[191] D.W. Hwang, H.G. Kim, J. Kim, K.Y. Cha, Y.G. Kim, J.S. Lee, Photocatalytic water splitting over highly donor-doped (110) layered perovskites, Journal of Catalysis 193(1) (2000), pp. 40-48.

[192] L. Garay-Rodríguez, L. Torres-Martínez, E. Moctezuma, Photocatalytic performance of K2Ti6O13 whiskers to H2 evolution and CO2 photo-reduction, Journal of Energy Chemistry 37 (2019), pp. 18-28. 
[193] J. Hemminger, R. Carr, G. Somorjai, The photoassisted reaction of gaseous water and carbon dioxide adsorbed on the SrTiO 3 (111) crystal face to form methane, Chemical Physics Letters 57(1) (1978), pp. 100-104.

[194] L. Huang, H. He, B. Zhang, S. Tan, J. Qi, Improved Photocatalytic Hydrogen Production Performance Over NaTaO3/Reduced Graphene Oxide Composite Photocatalyst, Journal of nanoscience and nanotechnology 18(7) (2018), pp. 4982-4986.

[195] Z. Huang, K. Teramura, H. Asakura, S. Hosokawa, T. Tanaka, Flux method fabrication of potassium rare-earth tantalates for $\mathrm{CO} 2$ photoreduction using $\mathrm{H} 2 \mathrm{O}$ as an electron donor, Catalysis Today 300 (2018), pp. 173-182.

[196] M. Halmann, M. Ulman, B. Aurian-Blajeni, Photochemical solar collector for the photoassisted reduction of aqueous carbon dioxide, Solar Energy 31(4) (1983), pp. 429-431.

[197] S.K. Parayil, A. Razzaq, S.-M. Park, H.R. Kim, C.A. Grimes, S.-I. In, Photocatalytic conversion of CO 2 to hydrocarbon fuel using carbon and nitrogen co-doped sodium titanate nanotubes, Applied Catalysis A: General 498 (2015), pp. 205-213.

[198] J. Kou, J. Gao, Z. Li, H. Yu, Y. Zhou, Z. Zou, Construction of Visible-Light-Responsive SrTiO3 with Enhanced CO2 Adsorption Ability: Highly Efficient Photocatalysts for Artifical Photosynthesis, Catalysis Letters 145(2) (2015), pp. 640-646.

[199] T. Ohno, N. Murakami, T. Koyanagi, Y. Yang, Photocatalytic reduction of CO2 over a hybrid photocatalyst composed of WO3 and graphitic carbon nitride (g-C3N4) under visible light, Journal of CO2 Utilization 6 (2014), pp. 17-25.

[200] A. Lais, M. Gondal, F. Al-Adel, CO2 photocatalytic reduction to fuels: Enhanced methanol selectivity by loading Ag on NaNbO3, AIP Conference Proceedings, AIP Publishing, (2018), p. 020013.

[201] D.-S. Lee, H.-J. Chen, Y.-W. Chen, Photocatalytic reduction of carbon dioxide with water using InNbO 4 catalyst with $\mathrm{NiO}$ and $\mathrm{Co} 3 \mathrm{O} 4$ cocatalysts, Journal of Physics and Chemistry of Solids 73(5) (2012), pp. 661-669. 
[202] X. Li, W. Li, Z. Zhuang, Y. Zhong, Q. Li, L. Wang, Photocatalytic reduction of carbon dioxide to methane over SiO2-pillared HNb3O8, The Journal of Physical Chemistry C 116(30) (2012), pp. $16047-16053$

[203] P. Li, S. Ouyang, G. Xi, T. Kako, J. Ye, The effects of crystal structure and electronic structure on photocatalytic $\mathrm{H} 2$ evolution and $\mathrm{CO} 2$ reduction over two phases of perovskite-structured $\mathrm{NaNbO} 3$, The Journal of Physical Chemistry C 116(14) (2012), pp. 7621-7628.

[204] P. Li, S. Ouyang, Y. Zhang, T. Kako, J. Ye, Surface-coordination-induced selective synthesis of cubic and orthorhombic NaNbO 3 and their photocatalytic properties, Journal of Materials Chemistry A 1(4) (2013), pp. 1185-1191.

[205] D.-S. Lee, Y.-W. Chen, Photocatalytic reduction of carbon dioxide with water on InVO 4 with $\mathrm{NiO}$ cocatalysts, Journal of CO2 Utilization 10 (2015), pp. 1-6.

[206] H. Cheng, B. Huang, Y. Liu, Z. Wang, X. Qin, X. Zhang, Y. Dai, An anion exchange approach to Bi2WO6 hollow microspheres with efficient visible light photocatalytic reduction of CO2 to methanol, Chemical Communications 48(78) (2012), pp. 9729-9731.

[207] I.A. Mkhalid, Preparation and characterization of NaBiO 3 nanopowders by different methods for photocatalytic reduction of CO 2, Ceramics International 40(4) (2014), pp. 5795-5800.

[208] X. Chang, J. Zheng, M. Gondal, G. Ji, Photocatalytic conversion of CO2 into value-added hydrocarbon (methanol) with high selectivity over ZnS nanoparticles driven by 355-nm pulsed laser, Research on Chemical Intermediates 41(2) (2015), pp. 739-747.

[209] W. Jiang, X. Yin, F. Xin, Y. Bi, Y. Liu, X. Li, Preparation of CdIn 2 S 4 microspheres and application for photocatalytic reduction of carbon dioxide, Applied Surface Science 288 (2014), pp. 138-142.

[210] T. Baran, S. Wojtyła, A. Dibenedetto, M. Aresta, W. Macyk, Zinc sulfide functionalized with ruthenium nanoparticles for photocatalytic reduction of CO 2, Applied Catalysis B: Environmental 178 (2015), pp. 170-176. 
[211] R. Zhao, J. Gao, S. Mei, Y. Wu, X. Wang, X. Zhai, J. Yang, C. Hao, J. Yan, Facile synthesis of graphitic C3N4 nanoporous-tube with high enhancement of visible-light photocatalytic activity, Nanotechnology 28(49) (2017), p. 495710.

[212] K. Kočí, L. Matějová, O. Kozák, L. Čapek, V. Valeš, M. Reli, P. Praus, K. Šafářová, A. Kotarba, L. Obalová, ZnS/MMT nanocomposites: The effect of ZnS loading in MMT on the photocatalytic reduction of carbon dioxide, Appl. Catal. B: Environ. 158-159 (2014), pp. 410-417.

[213] J. Chen, S. Qin, G. Song, T. Xiang, F. Xin, X. Yin, Shape-controlled solvothermal synthesis of Bi $2 \mathrm{~S} 3$ for photocatalytic reduction of CO 2 to methyl formate in methanol, Dalton Transactions 42(42) (2013), pp. 15133-15138.

[214] M.F. Ehsan, M.N. Ashiq, T. He, Hollow and mesoporous ZnTe microspheres: synthesis and visible-light photocatalytic reduction of carbon dioxide into methane, RSC Advances 5(8) (2015), pp. 6186-6194.

[215] A.T. Najafabadi, Emerging applications of graphene and its derivatives in carbon capture and conversion: Current status and future prospects, Renewable and Sustainable Energy Reviews 41 (2015), pp. 1515-1545.

[216] H.-C. Hsu, I. Shown, H.-Y. Wei, Y.-C. Chang, H.-Y. Du, Y.-G. Lin, C.-A. Tseng, C.-H. Wang, L.-C. Chen, Y.-C. Lin, Graphene oxide as a promising photocatalyst for CO 2 to methanol conversion, Nanoscale 5(1) (2013), pp. 262-268.

[217] P. Kumar, H.P. Mungse, S. Cordier, R. Boukherroub, O.P. Khatri, S.L. Jain, Hexamolybdenum clusters supported on graphene oxide: Visible-light induced photocatalytic reduction of carbon dioxide into methanol, Carbon 94 (2015), pp. 91-100.

[218] R. Gusain, P. Kumar, O.P. Sharma, S.L. Jain, O.P. Khatri, Reduced graphene oxide-CuO nanocomposites for photocatalytic conversion of $\mathrm{CO} 2$ into methanol under visible light irradiation, Applied Catalysis B: Environmental 181 (2016), pp. 352-362.

[219] J. Mao, T. Peng, X. Zhang, K. Li, L. Ye, L. Zan, Effect of graphitic carbon nitride microstructures on the activity and selectivity of photocatalytic $\mathrm{CO} 2$ reduction under visible light, Catalysis Science \& Technology 3(5) (2013), pp. 1253-1260. 
[220] S.J. Shi, S.S. Zhou, S.Q. Liu, Z.G. Chen, Photocatalytic activity of erbium-doped CeO2 enhanced by reduced graphene Oxide/ $\mathrm{CuO}$ cocatalyst for the reduction of $\mathrm{CO} 2$ to methanol, Environmental Progress \& Sustainable Energy 37(2) (2018), pp. 655-662.

[221] A.O. David, photoreduction of carbon dioxide to methanol using copper modified carbon nitride and titanium dioxide nanocomposites, Universiti Teknologi Malaysia, 2016.

[222] L. Liang, F. Lei, S. Gao, Y. Sun, X. Jiao, J. Wu, S. Qamar, Y. Xie, Single unit cell bismuth tungstate layers realizing robust solar $\mathrm{CO} 2$ reduction to methanol, Angewandte Chemie International Edition 54(47) (2015), pp. 13971-13974.

[223] A. Yahaya, M. Gondal, A. Hameed, Selective laser enhanced photocatalytic conversion of CO2 into methanol, Chemical physics letters 400(1-3) (2004), pp. 206-212.

[224] J. Mao, T. Peng, X. Zhang, K. Li, L. Zan, Selective methanol production from photocatalytic reduction of $\mathrm{CO} 2$ on $\mathrm{BiVO} 4$ under visible light irradiation, Catalysis Communications 28 (2012), pp. 38-41.

[225] W. Dai, H. Xu, J. Yu, X. Hu, X. Luo, X. Tu, L. Yang, Photocatalytic reduction of CO 2 into methanol and ethanol over conducting polymers modified Bi 2 WO 6 microspheres under visible light, Applied Surface Science 356 (2015), pp. 173-180.

[226] X. Li, J. Chen, H. Li, J. Li, Y. Xu, Y. Liu, J. Zhou, Photoreduction of CO2 to methanol over Bi2S3/CdS photocatalyst under visible light irradiation, Journal of Natural Gas Chemistry 20(4) (2011), pp. 413-417.

[227] J.-Y. Liu, B. Garg, Y.-C. Ling, CuxAgyInzZnkSm solid solutions customized with RuO2 or $\mathrm{Rh} 1.32 \mathrm{Cr} 0.66 \mathrm{O} 3$ co-catalyst display visible light-driven catalytic activity for $\mathrm{CO} 2$ reduction to $\mathrm{CH} 3 \mathrm{OH}$, Green Chemistry 13(8) (2011), pp. 2029-2031.

[228] X.-J. Lv, W.-F. Fu, C.-Y. Hu, Y. Chen, W.-B. Zhou, Photocatalytic reduction of CO 2 with $\mathrm{H} 2 \mathrm{O}$ over a graphene-modified $\mathrm{NiO}$ x-Ta 2 O 5 composite photocatalyst: coupling yields of methanol and hydrogen, RSC Advances 3(6) (2013), pp. 1753-1757. 
[229] V.S. Vyas, V.W.-h. Lau, B.V. Lotsch, Soft Photocatalysis: Organic Polymers for Solar Fuel Production, Chemistry of Materials 28(15) (2016), pp. 5191-5204.

[230] S. Ghasimi, Conjugated porous polymers for visible-light photocatalysis, Johannes GutenbergUniversität Mainz, 2016.

[231] R.A. Ricchi Jr, J.S.C. Campos, Photoactive Polymeric Blends for Solar Cells.

[232] D.H. Apaydin, E. Tordin, E. Portenkirchner, G. Aufischer, S. Schlager, M. Weichselbaumer, K. Oppelt, N.S. Sariciftci, Photoelectrochemical Reduction of CO2 Using Third-Generation Conjugated Polymers, ChemistrySelect 1(6) (2016), pp. 1156-1162.

[233] M.A. Rosen, Environmental sustainability tools in the biofuel industry, Biofuel Research Journal 5(1) (2018), pp. 751-752. 